\title{
LA CONDUCTA COOPERATIVA DE LAS PARTES \\ EN EL PROCESO CIVIL Y LA REBELDÍA: HACIA SU ADECUADA REGULACIÓN EN LA NUEVA JUSTICIA CIVIL CHILENA
}

\author{
COOPERATIVE BEHAVIOR OF PLAINTIFF AND DEFENDANT \\ IN CIVIL PROCEDURE AND REBELLION: TOWARDS AN \\ APPROPRIATE REGULATION IN THE NEW CHILEAN JUSTICE
}

\section{Fernando Orellana Torres* Álvaro Pérez Ragone**}

RESUMO: Los juicios en rebeldía son pronunciamientos vinculantes a favor del demandante ante la falta de respuesta del demandado no respondiendo o no compareciendo. Su regulación es una importante herramienta para la aceleración del proceso y la posibilidad de poder pronunciar y ordenar el cumplimiento de determinadas resoluciones cuando se verifican sus presupuestos. Permite igual acceder a una sentencia con valor de cosa juzgada. La rebeldía explica los puntos de contacto entre la autoridad y la participación como su interacción. El poder de adjudicación fundado en una discusión o controversia real en un proceso debe prever la falta de cooperación igualmente para no impedir la prosecución y conclusión del proceso. Muchos son los elementos que interactúan para un proceso civil moderno y efectivo.

PALABRAS CLAVES: cooperación; rebeldía; proceso civil; Derecho procesal civil comparado.

* Profesor de Derecho Procesal de la Universidad Católica del Norte. Antofagasta. Doctor (C) Facultad de Derecho de la Universidad de Zaragoza (España)

** Profesor de Derecho Procesal Civil de la Pontificia Universidad Católica de Valparaíso, LL.M. y Doctor en Derecho (Universidad de Colonia/Alemania),
ABSTRACT: Default judgments are judgments binding judgments in favor of the plaintiff when the defendant has not responded to a summons or has failed to appear before a court. Their regulation is an important tool of accelerating the legal process and is able to open the enforcing procedure, issued by the civil court or its chancery when certain conditions are met. Primarily it allows for recourse to the court's execution process; it also is final, like all judgments, and it leads to estoppel by res judicata. The default explains main points between participation and authority and their interaction. The foundations of the constitutional theory of judicial power and the adjudication supported on a real discussion in a legal process should answer the default of cooperation too, in order to the prosecution and conclusion any procedure. Many elements collaborate holistic in the creation of modern and effective civil procedural. Artículo publicado en la Revista de Derecho Ius et Praxis 2008, II.

KEYWORDS: procedural cooperation; default judgments; civil procedure; comparative civil procedure. 


\section{INTRODUCCIÓN}

El proceso civil se fundamenta sobre la conducta participativa de quien pretende y contra quién se pretende. Esto se da dentro de la relación triangular entre acción, proceso y jurisdicción ${ }^{1}$. El servicio de Justicia Civil que brinda el Estado es un recurso cuya distribución e impartición genera costos sociales, políticos y económicos, precisa de un tiempo para poder funcionar y genera un resultado (sentencia) adjudicatario asentado en el proceso como andarivel de funcionamiento de la jurisdicción ${ }^{2}$. Un sistema de Justicia Civil puede ser más o menos eficiente en los parámetros mencionados según el diseño de sus normas procesales funcionales. Estas debieran incentivar positivamente la participación de los interesados, con minimización de tiempo y costos para obtener un resultado aceptable para los interesados. A comienzos del siglo XIX esta ecuación de adecuada combinación de costo, tiempo y resultado era considerada como fundamental. ${ }^{3}$ Igual ratificación recibe luego en la reforma procesal civil austriaca ${ }^{4}$. Sigue vigente bajo el Análisis Económico del

1 Zuckerman, Adrian., Civil Procedure, Lexisnexis, Londres, 2003, pp. 1-10.

2 Andrews, Neil., "Accelerated Justice under the English Civil Procedural Rules”, ZZPInt, vol., 7, 2002, p. 79; Baumgärtel, Gottfreid, "Ausprägung der prozessualen Grundprinzipien der Waffengleichheit und der fairen Prozessführung im zivilprozessualen Beweisrecht", en Festschrift Matscher, Manz, Viena, 1998 , p. 29 y ss.

3 Bentham, Jeremy., Rationale of Judicial Evidence Specially Applied to English Practice, J.S. Mill (Ed.) Londres, 1827, v.1, p. 34

4 Klein, Franz, "Zeit- und Geistesströmungen", en Reden, Vorträge, Aufsätze, Briefe, Manz, Viena, 1927.
Derecho SHAVELL ${ }^{5}$. Tres visiones diferentes en el tiempo con una misma proyección.

Pero estos incentivos positivos no son suficientes si no se complementan con otros negativos que impidan la dilación indebida, que frenen el uso y abuso del servicio de justicia por una de las partes en detrimento de la otra y en definitiva de la funcionalidad de la propia Justicia Civil ${ }^{6}$.

El proceso, como instituto constitutivo del Derecho Procesal junto con la acción y la jurisdicción, debe velar en definitiva por el tiempo, el costo y su resultado en los marcos de la instrumentalidad y el contradictorio ${ }^{7}$. El primer marco, en tanto las normas procesales no son un fin en sí mismo, sino que están preordenadas a la realización del derecho sustantivoy-a través de este y primordialmente por el prisma de las Constituciones - de la Justicia de la causa con razonabilidad temporal $^{8}$. El segundo, pues los códigos procesales son la reglamentación del derecho

5 Shavell, Steven, Civil Procedure and Society, Joumal of Legal Studies, 1997, 606; sobre el pensamiento de la eficiencia en la prestación de justicia ver la obra de Fiz-Fierro, Héctor, Tribunales, justicia y eficiencia, UNAM, Méjico, 2006, esp. pp. 329-332

6 Resnik, Judith, Process of the Law, Foundation Press, Nueva York, 2004, p. 5 y s.; Fasching, Hans., "Die Bedeutung des Gleichheitssatzes für das zivilgerichtliche Verfahren", en Grund- und Freiheitsrechte in der gerichtlichen Praxis- Richterwoche, Manz, Viena, 1992, p. 339.

Cadiet, Loïc, "Civil Justice Reform: Access, Cost and Delay" en Civil Justice in Crisis: Comparative Perspectives of Civil Procedure, Oxford University Press, Oxford, 1999, p. 54.

8 Hazard Jr., Geoffrey, "Court Delay: Toward New Premises", en Civil Justice Quarterly, vol. 5, 1986, p. 236; Zuckerman, Adrian, "Dismissal for Delay - the Emergence of a New Philosophy of Procedure", (1998) 17 Civil Justice Quarterly, p. 223 
constitucional de acción y defensa dentro de una igual protección judicial. Ambos funcionarían como un sistema de checks and balances toda vez que el uno encuentra su límite en el otro confrontándose permanentemente para lograr un adecuado equilibrio ${ }^{9}$. Entonces, formulando concretamente la hipótesis quedaría del siguiente modo: el debido proceso, particularmente desde la óptica sustantiva (razonabilidad), como conjunto de garantías que es, comprende en su seno a la instrumentalización ${ }^{10}$.

La relación procesal comprende a diversos tipos de imperativos (deberes, cargas, obligaciones) para el vínculo de las partes entre sí y entre éstas y el órgano jurisdiccional. Ahora bien, no siempre las partes asumirán una conducta cooperativa, muchas veces por el contrario asumen conductas obstructivas o de omisión para la normal prosecución del proceso $^{11}$. De no verificarse una conducta cooperativa deben preverse mecanismos sustitutivos para evitar el estancamiento del proceso, lo que finalmente se traduce en la imposibilidad de obtener una debida tutela

9 De Oliveira, Carlos Alberto Alvaro, "O Formalismo-Valorativo no confronto com o formalismo excessivo", en Revista Forense n. 388 (2007), pp. 11-98.

${ }^{10}$ Fasching, Hans, "Rechtliches Gehör und Rationalisierung des zivilgerichtlichen Verfahrens in Österreich“, en Festschrift Hideo Nakamura, Seibundo, Tokyo, 1996, p. 133; Matscher, Franz, "Zum Problem der überlangen Verfahrensdauer in ZivilrechtssachenArt. 6 Abs. 1 EMRK und das österreichische Zivilgerichtliche Verfahren", en Festschrift Fasching, Manz, Viena, 1988, p. 21.

${ }^{11}$ Lent, Friedrich., "Die Verteilung der Verantwortlichkeit unter Gericht und Parteien im Zivilprozess“, en ZZP 63 (1943), p. 1 jurisdiccional $^{12}$. El grado de colaboración de las partes varía en importancia y su inejecución trae aparejada distintas consecuencias en intensidad: así difieren las consecuencias para el demandado que nunca compareció de aquel que deja de participar en determinados actos procesales. $\mathrm{O}$, cuando una de las partes no presta la colaboración requerida para la producción de determinada prueba. Los grados van desde una colaboración imperfecta hasta directamente una falta absoluta y esencial de colaboración. El fenómeno de la falta de colaboración de una de las partes en términos absolutos es el fenómeno que será aquí tratado y concentrado especialmente en la reticencia del demandado a participar en su calidad de tal habiendo sido debidamente requerido para ello ${ }^{13}$.

La actividad o defecto de actividad colaborativa de una de las partes da lugar a distintas regulaciones procedimentales. El denominado proceso, en rebeldía" se basa en la falta de colaboración esencial de una de las partes, permitiendo que se pueda arribar igualmente a una sentencia que ponga fin al proceso. Ello siempre que se haya respetado el debido proceso, tanto para la parte que continuó colaborando activamente como para aquella que dejó de hacerlo. La necesidad de regular una eventualidad procesal como la descrita y cómo es finalmente regulada se convierten en un mecanismo relevante para generar incentivos negativos y positivos, los que tienen directa incidencia con la preclusión,

${ }^{12}$ Hazard Jr., Geoffrey, "Rationing Justice", Journal of Law and Economics, vol. VIII, 1965, pp. 1-10.

${ }^{13}$ Lent, Friedrich, "Zur Untersuchung von Lasten und Pflichten der Parteien im Zivilprozes", en ZZP 67 (1954), p. 344. 
celeridad y economía procesal. El "incumplimiento" o "inejecución" en tanto falta de colaboración esencial en el proceso tiene una regulación diferente de la que puede asumir en el derecho sustantivo. La relación procesal que es independiente, aunque tiene en vista instrumentalizar una relación sustancial, necesita acudir a técnicas que puedan justificar el arribo a una sentencia definitiva que extinga el proceso la actuación unilateral de una de las partes. De esta manera se presenta el proceso en rebeldía, como una alternativa procesal fundada en la inactividad procesal de una de las partes (preferentemente del requerido). La inactividad o falta de colaboración esencial de una de las partes no puede impedir la resolución de la causa. Más aún puede sostenerse que la sola voluntad participativa de uno de los interesados puede resultar suficiente para justificar la sentencia con la tutela jurisdiccional requerida. La voluntad participativa (real al menos de una de la partes, ficta del rebelde) sirve de asiento para legitimar una resolución que en los hechos se construyó sobre la actividad de una sola de las partes ${ }^{14}$. La necesidad de una tutela procesal tempestiva, dentro de un plazo razonable, no desplaza así a la seguridad y certeza sino que la complementa ${ }^{15}$.

${ }^{14}$ Comp. Volpino, Diego, "Contraddittorio Ed Impugnazione Incidentale Nel Procedimento Contumaciale", 2001, en NGCC, p 713 especialmente sobre la combinación entre "giusto processo" de la Constitución (art. 111) y el imperativo de "più sollecito e leale svolgimento del processo"; igualmente Lebre de Freitas, José., "Le respect des droits de la défense lors de l'introduction de l'instance", en L'efficacité de la Justice Civile en Europe, Larcier, Bruxellas, 2000, p. 13.

15 Didone, Antonio, Equa riparazione e ragionevole durata del processo, Giuffrè, Milano 2002, p. 171; Zuckerman, Adrian, "Dismissal for Delay - the Emergence of a New Philosophy of Precedure" (1998) 17 Civil Journal Quaterly, p. 223
El fenómeno de la rebeldía ha recibido una pluralidad de tratamientos legislativos en la historia y el derecho comparado. El recurso al derecho comparado no persigue simplemente comparar normas, sino más bien sistemas que responden a una realidad histórica y cultural diversa. Es por ello que se procura dar una explicación de trasfondo y no simplemente de comparación de normas o su mero "legal transplant"16. Comparar soluciones para un mismo problema permite analizar alternativas adecuadas de las poco funcionales. Este artículo pretende abordar el instituto desde una perspectiva comparada y de dogmática procesal interdisciplinaria, para proponer conclusiones sobre la necesidad de una regulación adecuada en la reforma de la justicia civil chilena. Se ha de concentrar en la conducta no cooperativa del demandado o requerido no tratándose la de la contraparte (demandante). El recurso del derecho comparado no persigue simplemente comparar normas, sino más bien sistemas que

${ }^{16}$ Se suele defenestrar el uso del Derecho Comparado a veces con razón cuando simplemente se propugnan "transplantes" legales, sin ignorar que igualmente existen "anticuerpos" dentro de cada sistema que pueden provocar rechazo de instituciones que en otro sistema funcionan (especialmente Kahn-Freund, Otto, "On Uses and Misuses of Comparative Law" (1974) Vol. 37 Modern Law Review, p. 1). En este artículo se pretende presentar un problema común en otros sistemas para luego describir y analizar críticamente las distintas soluciones. Con este alcance es que se acude al método comparatista. Ver Fix-Fierro, Hector, "Tendencias actuales del derecho comparado", en Metodología del derecho comparado, UNAM, Méjico 2005, pp. 23-68;; Cappelletti, M- Kollmer, PJ-Olson, JM, The Judicial Process in Comparative Perspective, Oxford Univ. Press, Oxford, 1989, pp. 12-24; Langer, Maximo, "From Legal Transplants to Legal Translations: The Globalization of Plea Bargaining and the Americanization Thesis in Criminal Procedure", en Harvard International Law Journal, Vol. 45, No. 1, 2004. 
responden a una realidad histórica y cultural diversa. Es por ello que se procura dar una explicación de trasfondo y no simplemente de comparación de normas. En una primera parte se desarrollan los puntos relevantes en la regulación de la rebeldía con una visión holística e interdisciplinaria del fenómeno. Se plantean respuestas que permiten en desarrollo de la tercera y cuarta parte en torno a los sistemas procesales de la contradictorio ficto y confesión ficta respectivamente. En la quinta parte se presenta el modelo híbrido inglés y en la sexta el modelo chileno. Una séptima parte desarrolla argumentos críticos de lege lata y ferenda acudiendo a soluciones que se consideran las aceptables. Una última parte contiene las conclusiones

\section{LA IMPORTANCIA DE LA REGULACIÓN ADECUADA DE LAS CONDUCTAS NO COOPERATIVAS DE LAS PARTES EN EL PROCESO CIVIL}

En Europa la rebeldía no ha sido ignorada como un dato preocupante en los últimos quince años habiendo sido considerada en diferentes documentos, directivas y proyectos de reglamentos. Su íntima vinculación con la "mora en las obligaciones" y el impacto económico que genera un proceso en rebeldía han sido los puntos centrales de resonancia. Desde el libro verde hasta las propuestas finales para la regulación de un proceso monitorio para Europa se menciona y que elevado índice de rebeldía ${ }^{17}$. Este dato no es

17 Especialmente dentro del Proceso Civil Comunitario la rebeldía ha sido un fenómeno relevante no ignorado. No solo como un problema procesal, sino especialmente económico dentro del marco de la lucha ajeno a otras realidades, entre ellas la chilena. El elevado índice no debiera ser preocupante si la respuesta normativa lograra dar una solución aceptable que contemple adecuadamente la inactividad sin perjudicar la debida diligencia de colaboración de la contraparte. Por solución aceptable debe entenderse aquélla que incentive negativamente la falta de colaboración esencial con claras, sencillas y expeditas consecuencias desfavorables para el rebelde. De esta manera se logra una respuesta disuasiva y efectiva: quien planea una inactividad procesal absoluta sabrá con certeza las consecuencias, quien ha conservado su conducta cooperativa tendrá un seguro resguardo procesal. No debe tampoco olvidarse que un proceso en rebeldía implica

contra la mora en el cumplimiento de las obligaciones y los efectos perjudiciales dentro del tráfico comunitario. Una serie de directivas (DOUE. C. 323 de 21.11.1994, p. 19 u. COM (94) 207 3.6.1994; DO L 127 v. 10.6.1995 (consejo de la Comisión); Informe de diagnóstico y propuesta DOUE C. 287 v. 22.9.1997, p. 92; DOUE. Nr. C 168, 13. Ver in Zeitschrift s. Int. Priva.1998, 1614; DOUE. C. 33 del 31.1.1998, p. 3), pasando por un Libro Verde (COM (2002) 746)con propuestas reformas hasta el 2004, hasta las propuestas finales para la regulación de un proceso monitorio (con última modificación en el año 2006 (COM (2006)) para finalizar en el Reglamento del Título Ejecutivo Europeo (del año 2005) actualmente vigente ocuparon a los órganos, operadores y comunidad científica comunitaria en los últimos 20 años. Es que efectivamente quien no colabora participando en el proceso no puede impedir que ello perjudique a la parte que fue diligente (Corte Europea de Derechos Humanos, NJW, vol. 1995, p. 1413; Corte Europea de Derechos Humanos 1994/28; Comp. in re Pérez de Rada Cavanilles c. España, Reports CEE, 1998, § 39; enfático el caso Porter v. Magill in [2002] 1 All ER 465, HL, p. 87, 106. 114; Corte Europea de Derechos Humanos, 1994/28 (MRK); Comp. House of Lord (England) los casos: Bentham (Corte Eu. Der. Hum), en EuGRZ año 1986, p. 299), Le Compte (Corte Europea de Derechos Humanos (EGMR), EuGRZ año 1981, p. 551) 
un costo para la administración de justicia pudiendo convertirse en una innecesaria fuente de erogación en tiempo y recursos sumado a las sobrecarga y saturación para los tribunales. ${ }^{18}$

1. En el supuesto de inactividad cooperativa esencial de una de las partes las soluciones que brinde el ordenamiento procesal tienen directa vinculación con diferentes principios. A cuáles de estos se les da primacía en detrimento de otros tiene especial relevancia al momento de la regulación de la técnica procesal adecuada. ¿Cómo pueden conciliarse la seguridad, la celeridad, la economía con el grado de certeza jurídica que puede lograrse escuchando a las dos partes y arribando a un convencimiento de los hechos alegados para el logro de la minimización del error en la calificación jurídica de estos? Tal como se desarrollará los requisitos para que la inactividad revista la calidad de rebeldía (o contumacia ${ }^{19}$ ) varían en intensidad. Varios interrogantes determinan las distintas alternativas de regulación. Un primer interrogante será ver cuales omisiones

18 Schima Hans, Die Versäumnis im Zivilprozess, Kleinfeller, Viena, p. 3; Kargados, Panagiotis, Die Probleme des Versäumnisverfahrens : eine rechtsvergleichende Untersuchung anläßlich des neuen griechischen Versäumnisverfahrens, FUBerlin, Berlin, 1970, p. 1; Comp. Lebre de Freitas José, "Le respect des droits de la défense", op. Cit., Nums. 15-16

${ }_{19}$ Términos con distinto significado histórico en los que no se ahondará en esta oportunidad. Contumacia implicó desde su empleo inicial la incomparecencia y falta total de cooperación. Así empleado el término inicialmente por Hermogenian (late $3^{\text {rd }}$ century) in D. 42.1.53.1: "Contumax est, qui tribus edictis propositis vel uno pro tribus, quod vulgo perentorium appellatur, litteris evocatus praesentiam suam facere contemnet", desarrolla este argumento en detalle Steinwenter, Anton, Studien zum römischen Versäumnisverfahren, Beck München, 1914, pp. 1-35. son presupuestos para el estado de rebeldía. En un modelo la sola ausencia a cualquier audiencia es un supuesto necesario y suficiente, en otro requerirá además que la inactividad se refiera a un acto procesal relevante como ser la no contestación y comparecencia frente a una demanda interpuesta y debidamente notificada ${ }^{20}$. Un segundo interrogante se vincula con las partes que pueden incurrir en rebeldía: demandante o demandado, nos estaremos refiriendo como susceptibles por su inactividad ser declarados en rebeldía. Un tercer interrogante se relaciona con los efectos inmediatos del estado de rebeldía. Aquí es donde se histórica y comparativamente se mencionan dos grandes tendencia. Una que recepta la, "litis contestatio“21 (de origen romano-canónica) como eje y con ella construye una estructura consecuente en la que la inactividad del requerido tiene por significado la oposición a todo lo alegado por la contra parte (ficta litis contestatio). La otra de origen germano donde la inactividad tiene un efecto positivo, ello es la confesión tácita reconociendo como verdaderos los hechos alegados por la contra parte (ficta confessio). Como puede inferirse

\footnotetext{
${ }^{20}$ Por ejemplo el autor español Joan Vergé Grau brinda una definición de la rebeldía en base a este modelo: “.. la rebeldía es un estado único e irrepetible; supone ausencia inicial del demandado e inactividad total, por lo menos en la fase declarativa, la personación, aún extemporánea, termina con la rebeldía." (La rebeldía en el proceso civil, Bosch, Barcelona, 1989 p.54).

${ }^{21}$ Ver sobre en detalle detalle Fairén Guillén, Victor, El juicio ordinario y los procesos rápidos, Barcelona: Bosch, 1953, p. 149 y ss.; Fairén Guillén, Victor, El desistimiento y su bilateralidad en primera Instancia (contra la doctrina de la litis contestatio), Barcelona, Bosch, 1950, pp. 69-77. Ver igualmente Sohm Jr., Rudolf, Die Litis Contestatio in Ihrer Entwiclung vom frühen -Mittelalter bis zur Gegenwart, Munich, 1914, pp. 68 ss., 159 ss., 167 ss
} 
de estas dos alternativas en una (b) se torna innecesaria la etapa probatoria, pudiéndose arribar sin más a la posibilidad de dictar sentencia; mientras que la posibilidad (a) al partir de la total oposición a lo alegado por la contra parte, implica que todos los hechos son contradictorios y eventualmente en lo pertinente deberán ser probados ${ }^{22}$. Este tercer interrogante lleva consigo una serie consecuencias aparte de insumo temporal que pueda acarrear la apertura de una etapa probatoria. Los mecanismos de impugnación concedidos a la parte rebelde y eventualmente agraviada por una sentencia variarán según cual sea la alternativa que se acoja. El acceso a la alzada y la mayor o menor extensión de la cognición recursiva como la permisión o no de reingreso del rebelde serán también variables. ${ }^{23}$

2.La prescripción de consecuencias negativas para el supuesto de que las partes no respeten los límites temporales establecidos para la realización de sus actos cumple no sólo una finalidad represiva mediante la preclusión, a ello se le suma el efecto disuasivo para instar a una conducta de buena fe cooperativa. ${ }^{24}$. La organización procedimental del tiempo tiene como destinatarios no solo a las partes para que hagan valer sus derechos de agresión y defensa, sino que además al órgano jurisdiccional concreto para que pueda disponer previsiblemente del tiempo de trabajo en forma adecuada. El costo temporal del proceso es la base de una pluralidad de

\footnotetext{
${ }^{22}$ Kargados, Panagiotis, op. cit, p. 5 y ss.

${ }^{23}$ En detalle ver Schima Hans, op. Cit., 209 y ss.

${ }^{24}$ Goldschmidt, James, Der Prozess als Rechtslage, Springer, Berlin, 1925, pp. 103, 146.
}

principios procesales como así también de técnicas organizativas y funcionales para resguardar el ejercicio debido y efectivo de los derechos en el proceso. La omisión de una conducta cooperativa por una de las partes puede tener por consecuencia el cierre de la posibilidad para que la pueda efectuar en una etapa posterior ${ }^{25}$. Esta formulación básica a la cual responde la preclusión procesal puede tener distintas variantes de acuerdo a la gravedad de la consecuencia sancionatoria. Pero la descripción de la conducta no cooperativa y su consecuencia es relevante. Se debe continuar un proceso prescindiendo realmente de una de las partes pero acudiendo a ficciones que den una respuesta que garantice el transcurrir procesal de etapas e instancias sin que el capricho no cooperativo de uno pueda derivar en perjuicio del otro. Las dos grandes alternativas históricas y de derecho comparado precisamente funcionaron y funcionan como mecanismos de ficción. Ambas, la ficta confessio y la ficta litis contestatio pretenden responder calificando la conductas de la renuente a colaborar determinando consecuencias más o menos gravosas, más o menos eficientes ${ }^{26}$.

\section{EL SISTEMA DE LA FICTA CONFESSIO}

Laficta confessio se funda en la posibilidad y necesidad de decidir de acuerdo a lo alegado por la parte diligente. Así es consecuente con

${ }^{25}$ Clayton, Richard-Tomlinson, Hugh, Fair Trial Rights, Oxford University Press, Oxford, 2001, pp. 8-20.

${ }^{26}$ Para una teoría general del Derecho de la rebeldia como tema autónomo en el proceso civil ver Bülow Oskar, Das Geständnissrecht: Ein Beitrag zur allgemeinen Theorie der Rechtshandlungen, Mohr, Freiburg, pp. 1-21. 
el premiar la conducta cooperativa de las partes con el proceso haciendo valer sus medios de agresión o defensa. De esta forma los hechos alegados por una de las partes se consideran como aceptados y reconocidos por la otra que habiendo tenido oportunidad para controvertirlos y en su caso probar en forma contraria, no lo hizo ${ }^{27}$. Aún cuando efectivamente pueda sostenerse que la interpretación procesal de la falta de colaboración tiene por consecuencia que determinados hechos se tengan por reconocidos y que ellos simplemente responden a una ficción. O sea, muy bien pueden no corresponderse con una realidad expresamente alegada y fictamente reconocida, sobre la que se asentará una sentencia. De este modo se podría sostener que el proceso civil no puede sujetarse al capricho o estrategia cooperativa de una de las partes en detrimento de la otra. En los hechos siempre entran en juego principios procesales que tienen sentido contrapuestos correspondiendo corresponde determinar una solución de técnica procesal proporcional, balanceada y razonable. La consecuencia gravosa por otro lado, que puede implicar una sentencia definitiva contraria a la parte rebelde se compensa con las posibilidades abiertas y flexibles de medios de impugnación recursivos o de oposición que permitan revisar la sentencia dictada y en su caso retrotraer el proceso a una instancia o etapa en la que se le permita a la parte perjudicada por su rebeldía hacer valer sus derechos precluidos de ejercicio ${ }^{28}$. De esta manera la

27 Comp. Kargados, Panagiotis op. Cit., p. 6; Lebre de Freitas, "Le respect des droits de la défense", op. Cit., Nums. 17-18.

${ }^{28}$ Kargados, Panagiotis, p. 7. rebeldía del demandado es considerada como confesión por la que se reconocen como verdaderas las alegaciones del demandante. Se considera que tiene lugar esta confesión no solamente por la no comparecencia a una audiencia sino incluso por el solo hecho que no manifestarse dentro de los plazos establecidos ${ }^{29}$.

Los modelos germanos han sido históricamente identificados como ejemplos de este modelo. Se fundaban y fundan en requisitos flexibles y no tan estrictos para la configuración de la rebeldía, y regulan consecuencias negativas en perjuicio del rebelde. Verificado el presupuesto de hecho de la rebeldía se consideraban como reconocidas las alegaciones unilaterales de la contraparte compareciente. La constricción de sujeción al proceso, que luego se vio traducida en forma de deber inicialmente y solo luego de carga ${ }^{30}$, tuvo una función inicialmente punitiva y por ende de gran efecto disuasivo en la Lex Sálica. De todas maneras es posterior la fundamentación no punitiva y con el solo objetivo de lograr una resolución definitiva del proceso sirviendo de motivación las alegaciones de la parte que compareció y su veracidad asentada en la confesión por ficción de la contraparte rebelde ${ }^{31}$. Aún cuando eran conocidas tanto

${ }^{29}$ Así Alemania, Suiza, Austria y Grecia (Kargados, Panagoti, op. Cit., pp. 184-186); de la misma manera Portugal, al respecto Lebre de Freitas, José, ” Le respect des droits de la défense", op. Cit., Num. 17.

${ }^{30}$ Comp. Lent, Friedrich, op. Cit., p. 346.

${ }^{31}$ La pregunta sobre la naturaleza de deber o carga del imperativo de comparecer fue tratada en profundidad en Alemania durante el siglo XIX con distintas posiciones al respecto. La esencia de las consecuencias que la rebeldía son objeto de tratamiento ya en la 
la ficta litis contestatio como la confessio finalmente se optó por esta segunda ${ }^{32}$.

1. En derecho vigente según el actual proceso civil alemán según $§ 331$ del ZPO alemana se consideran como verdaderas las alegaciones de hecho del demandante cuando emplazada la demandada no comparece y se tratan de derechos disponibles ${ }^{33}$. La ficción de la confesión

introducción de la obra de Degenkolb, Heinrich, (Einlassungszwang und Urteilsnorm, Druck und Verlag von Breitkopf und Härtel, Leipzig 1877, pp. 5-35 esp.) donde la imposición de participación procesal es considerada como un deber de las partes para con el Estado, no pudiendo estas obstaculizar o disponer no colaborar con el proceso. Según este autor el supuesto de hecho de la rebeldía debía ser examinado en dos niveles: por un lado de acuerdo a la decisión judicial en su faz sancionatoria, en tanto imposición de una consecuencia sancionatoria gravosa y punitiva para el rebelde (perjuicio para una de las partes consistente en la pérdida del proceso, de hecho el autor se refiere a una resolución de contenido penal) y por otro la sentencia en su carácter conclusivo del proceso pudiéndose fundar en el reconocimiento que efectúa una de las partes de lo alegado por la otra (Degenkolb, Heinrich, op. Cit., pp. 19-25); ver igualmente v. Hippel, Fritz, Wahrheitspflicht und Aufklärungspflicht der Parteien im Zivilproze $\beta$, Frankfurter Wissenschaftliche Beiträge. Rechts- und Wirtschaftswissenschaftliche Reihe, 1939, pp. 311-312). Contrarios a las consecuencias punitivas y penales de la rebeldía se pronunciaban Hahn, Bernhard, Kooperationsmaxime im Zivilprozess?: Grenzverschiebungen in Der Verantwortung Von Parteien Und Gericht Bei Der Tatsachenbeschaffung Und Sachverhaltserforschung Im Neuen Zivilprozessrecht?, Heymans, Colonia, 1983, p. 294 y Henckel, Wolfram, "Vorbeugender Rechtsschutz im Zivilrecht, AcP 174, p. 97, siendo que la sola sentencia condenatoria en rebeldía ya representa por sí misma una sanción contra el rebelde.

32 Ver al respecto Bülow Oskar, "Civilprozessualische Fiktionen und Wahrheiten“, AcP 62 (1879), p. 16.

33 Ver Prütting Hanns, MünchKomm/ZPO, § 331, Beck, Munich, 2002, Nums. 1-3, 4, 10-11. El proceso civil alemán distingue entre la negligencia procesal de aquel que abandona un proceso sin más, que permite la sentencia la rebeldía en los casos de los $§ \S 331$ ss. ZPO también está contenida en el proceso civil austriaco en tanto la no comparecencia de la parte se verifique desde el inicio del proceso y ella no se funde en motivos obstaculizantes debidamente acreditados. El mismo sistema fundado en la confesión ficta existe en el proceso civil de los distintos cantones en Suiza variando sí las distintas modalidades recursivas para contrarrestar sus efectos ${ }^{34}$. El proceso civil griego con influencia alemana recepta igualmente la ficción de la confesión en relación a los hechos alegados por la parte demandante. (Art. 282 CPC) ${ }^{35}$. Siendo flexibles y amplios los supuestos de hecho, correspondientemente se conceden a la parte perjudicada medios

del caso de los $\$ \S 331$ inciso 3, 276 inciso 1 y primera parte del inciso $2 \mathrm{ZPO}$, donde el demandado no ha manifestado su voluntad de querer defenderse contra la demanda. Si la sentencia se pronuncia según el $§ 331$ (o $\S 345$ ZPO) se verifica el caso de una verdadera sentencia en rebeldía, de acuerdo a la designación de la doctrina (ver Prütting, Hanns, op. Cit., § 330 Nums. 17-20; Linke, Helmut, Die Versäumnisentscheidung im deutschen, österreichischen, belgischen und englischen Recht, Gieseking, Bielefeld,, p. 33 y ss.). De esta forma el sistema alemán no conoce un sistema de „órdenes“ o „mandamientos” para participar en el proceso, sirviendo de suficiente naturaleza persuasiva y sancionatoria la rebeldía tal cual está regulada (Comp. Prütting Hans, MünchKomm/ZPO, § 338 Nums. 1-3; Münzberg, Wolfgang, Die Wirkungen des Einspruchs im Versäumnisverfahren, Bielefeld, Gieseking, 1959, p. 17 y ss.; Fasching, Hans, "Die Bedeutung des Gleichheitssatzes für das zivilgerichtliche Verfahren", en Grund- und Freiheitsrechte in der gerichtlichen Praxis-Richterwoche, Manz, Viena, 1992, p. 339

${ }^{34}$ Kargados, Panagiotis, op. Cit., pp. 130 s., 133 p.

${ }^{35}$ Kargados, Panagiotis, op. Cit., p. 102; Schubert, Werner, "Zur Rechtsgeschichte des Versäumnisverfahrens in der Zivilprozessordnung und zur weiteren Entwicklung bis zur Novele von 1976, FS Schneider, Herne, Berlín, 1997, Verlag für die Rechts- und Anwaltspraxis. p. 65 ss. (esp. 66-67). 
de impugnación extraordinario como la oposición y en algunos casos ordinarios como de apelación ${ }^{36}$

2. Hasta la reforma del año 2002 el proceso civil austriaco de rebeldía se fundaba en tres casos que, de acuerdo a los $\S \S 396$ ZPO austriaca podían conducir al dictado de una sentencia en rebeldía, a saber ${ }^{37}$ : rebeldía por no contestación de la demanda en el término de emplazamiento, rebeldía por no comparecencia a la audiencia preliminar y finalmente por no comparecencia a las audiencias de prueba ${ }^{38}$. Verificado el supuesto hecho de la incomparecencia de una de las partes, se consideran por acreditado lo alegado por la contraparte ${ }^{39}$ Con la reforma del año 2002 se reformuló el § 396 ZPO austriaca reduciéndose los casos de rebeldía a dos supuestos. Ambos declarables a petición de la parte que compareció: en primer lugar la rebeldía para el caso de no contestación en plazo de la demanda, segundo el supuesto de no comparecencia a una audiencia. Es posible incluso una sentencia en rebeldía antes de incluso por rebeldía en relación a actos posteriores en los que la parte compareció. Por cierto que las consecuencias de la rebeldía

${ }^{36}$ Kargados, Panagiotis, op. Cit., p. 115; Linke, Helmut, op. Cit., p. 41 y ss.

${ }^{37}$ Así Frauenberger, ÖJZ (2002), 873 ss. (874); Klicka, ZZPInt 7 (2002), 179 ss. (186); Hübner, Astrid Deixler, "Fortschritte und Rückschritte durch die Zivilverfahrensnovelle 2002", in FS Beys, Tomo I, Economica, Atenas, p. 209 ss. (215 ss. .).

${ }^{38}$ Rechberger/Simotta, ZPO, Rn. 562; Holzhammer, p. 204; Linke, Helmuth, op. Cit., p. 44 y ss.; comp. Hübner, Astrid Deixler, op. cit., p. 214.

${ }^{39}$ Holzhammer, p. 279 de modo que el $§ 396$ ZPO austriaco no se coresponde con el § 331, I ZPO alemán. no fueron modificadas por la reforma ${ }^{40}$. Aún con las similitudes en los supuestos de rebeldía y en las consecuencias, el modelo austriaco no contiene ninguna disposición explícita sobre la ficción de una confesión que sea comparable a la contenida en el ZPO alemana. En todo caso la versión austriaca es más gravosa que la alemana. Ello ya que ésta contiene referencias expresas en relación a que, al momento del dictado de la sentencia se deben considerar no solamente las pruebas presentadas y lo alegado, sino además ponderar la existencia o no de probabilidad de éxito de las mismas ${ }^{41}$. Difiriendo de la regulación alemana el modelo austriaco adopta una versión mucho más gravosa de las consecuencias de la rebeldía, en tanto la parte negligente en su comparecencia tiene imposibilidad absoluta para hacer valer sus medios de agresión o defensa. El pensamiento inicial de la violación de deberes procesales $\mathrm{y}$ las fuertes sanciones incluso con contenido originario punitivo fue sucesivamente disminuyendo y perdiendo su naturaleza y función sancionatoria mediante la inclusión del medio de impugnación de la oposición. Así solo excepcionalmente se admite la rescisión de lo obrado, la reposición y la apelación, más excepcionales aun ${ }^{42}$. Más

${ }^{40}$ Rechberger, Walter-Kodek, Georg, "General Report", in Order for Payment in the European Union, Kluwer, The Hague/London/New York, 2001, p. 1 y ss.; Frauenberger, Andreas, "Die ZVN 2002-Neuerungen im Zivilprozessrecht", ÖJZ 2002, p. 873 y ss.

${ }^{41}$ Klicka, Thomas, "Die österreichische Zivilverfahrens-Novelle 2002 als Versuch einer Verfahrensbeschleunigung - ein Vergleich zur deutschen ZPO-Reform 2002“, ZZPInt 7 (2002), p. 179 ss.

42 Steinhauer, Thomas, Versäumnisurteil in Europa: eine rechtsvergleichende Studie über die Versäumnisverfahren im deutschen, österreichischen, 
gravoso aun es el caso para revertir la confesión ficta en segunda instancias en Suiza - al menos en el cantón de Zurich mediante recursos ordinarios como el de apelación o reposición, solo habilitadas para casos extraordinarios. ${ }^{43}$.

\section{IV.SISTEMA DE LA FICTA LITIS CONTESTATIO}

El sistema de la ficta litis contestatio ${ }^{44}$ parte de la ficción de la oposición total del rebelde a lo alegado por la contraparte. Ello implica que no puede eludirse la necesidad de la faz probatoria. Si todo lo alegado por la parte no rebelde es considerado fictamente como objetado, porque no colabora con el proceso, todos los hechos invocados divienen en contradictorios y consecuentemente susceptibles de ser analizados por el juez a la luz de las exigencias probatorias. Es así que, por un lado pueden producirse pruebas vinculadas con alguno de los hechos, y por otro lado entran en juego las reglas de la carga de la prueba ${ }^{45}$. Precisamente por eso es que la controversia ficta, no genera mayor gravamen a la parte rebelde, gozado incluso de medios de impugnación ordinarios. Una

französischen, italienischen und englischen Recht anlässlich eines Entwurfs zur Schaffung einer einheitlichen europäischen Zivilprozessordnung, Frankfurt a. M., 1996.

${ }^{43}$ Fasching, Hans, "Der mühsame Weg zur Prozessbeschleunigung", in FS Beys, I, Economica, Atenas, 2003, p. 305 ss.

${ }^{44}$ Para un estudio detallado de la litis contestatio y sus efectos ver Sohm Jr., Rudolf, Die Litis Contestatio in Ihrer Entwiclung vom frühen Mittelalter bis zur Gegenwart, Munich, 1914, pp. 68 ss., 159 ss., 167 ss.

${ }^{45}$ Comp. Lebre de Freitas, José, "Le respect des droits de la défense", op. Cit., Nr. 19-22. vez que se produce la rebeldía (con o sin declaración judicial como requisito formal), comienza a funcionar el engranaje de la ficción habilitándose la posibilidad del dictado de una sentencia definitiva contradictoria. Por un lado se establecen exigentes requisitos para: primero podrá considerar a una de las partes como rebelde $\mathrm{y}$, segundo -consecuencia de lo primero- se tiene lo peticionado por controvertido fictamente abriéndose la etapa probatoria como un requisito eventual más antes de poder decidirse en el mérito. El efecto preclusivo para la contestatio ficta significa el cierre de la posibilidad para hacer valer por parte del demandado toda defensa de fondo o éxcepción procesal. Es precisamente la habilitación de la prueba que habilita al juez para que aprecie los hechos alegados como controvertidos, valore en su caso la prueba producida y pueda incluso dictar una sentencia en contra de la contaparte del rebelde. Recién contra la sentencia dictada rebeldía es posible interponer en mayor o menor amplitud recursos ordinarios de acuerdo a los distintos sistemas $^{46}$. Así lo alegado y en su caso probado unilateralmente por quien compareció, sirve de elemento necesario y suficiente para la motivación de la sentencia en rebeldía. Si la parte rebelde se considera agraviada por ella, en tanto del contradictorio ficto se pudo inferir el convencimiento necesario para una sentencia en favor de la contraparte, tendrá la posibilidad de poder impugnar y que se le habilite si procede un contradictorio real mediante el cual pueda revertir la sentencia adversa. Aún cuando tanto en Francia Italia España los hechos

\footnotetext{
${ }^{46}$ Steinhauer, Thomas, op. Cit., p. 149.
} 
alegados por la parte compareciente deben ser siempre sujetos a examen de fundabilidad por controvertidos, los requisitos y consecuencias de la litis contestatio son enfocados de distintas maneras ${ }^{47}$.

1- Hasta comienzos del siglo XII, la incomparecencia del demandado se había resuelto con la exigencia de fianzas o ejecución de prenda, asó ocurre en el Fuero Viejo de Castilla ${ }^{48}$ donde encontramos en su libro III, título primero, ley III, referencias a la rebeldía. En esta obra se condena al pago de multas al demandado que no "viene al emplazamiento". En la obra de Alfonso X, Las Partidas, encontramos referencia a la contumacia o rebeldía del demandado (Partida $3^{\mathrm{a}}$, Título III, Ley $1^{\mathrm{a}}$ ). La institución de la rebeldía, con características propias pasó, a la Novísima Recopilación, Ley de Enjuiciamiento Civil de 1855 y a la Ley de Enjuiciamiento de 1881. Hasta llegar a la actual Ley de Enjuiciamiento Civil del año 2000. La antigua Ley de Enjuiciamiento Civil de $1881^{49}$ reguló la institución procesal de la rebeldía en su libro II, título IV, intitulado $D e$ los juicios en rebeldía; artículos 762 a 78950,

${ }^{47}$ Steinhauer, Thomas, op. Cit., p. 156.

48 Alvarado Planas Javier y Oliva Manso Gonzalo. Los Fueros de Castilla, en Boletín Oficial del Estado. Centro de Estudios Políticos y Constitucionales, 2004, p. 557.

${ }^{49}$ En adelante ALEC

50 Aragoneses Alonso, Pedro. "Inactividad de las partes en el proceso civil", en Revista de Derecho Procesal, $1960 \mathrm{~N}^{\circ}$ 3. Bachmaier Winter Lorena. La Rebeldía en el proceso civil norteamericano y español. Servicios de publicaciones de la Facultad de Derecho de la Universidad Complutense, Madrid, 1994. Samanes Ara, Carmen. La tutela del rebelde en el proceso civil. JM Bosch Editor S.A., Barcelona, 1993. Vergé Grau, Juan. La rebeldía en el proceso civil. Librería Bosch, Barcelona, 1989. sin perjuicio de otras normas legales: artículos 281, 527, 528, 685 entre otras. El demandado una vez notificado de la demanda es libre de comparecer en el proceso. Si asumía esta posición de mantenerse inactivo estaba en rebeldía ${ }^{51}$. Esto suponía que en el proceso si bien existían dos partes, su continuación se realizaba con la única presencia de la parte actora. Esta actitud del demandado no significaba ni allanamiento ni reconocimiento de los hechos afirmados por el demandante. En la ALEC los presupuestos para que se diese la rebeldía en el proceso ${ }^{52}$ eran los siguientes: Notificación válida. Es decir la válida citación o emplazamiento del demandado; El demandado no comparece en el plazo legal. El sujeto pasivo del proceso no se ha personado en el plazo legal para realizar el acto procesal.Una vez producido estos presupuestos, se le declara en rebeldía, sin volver a realizar "diligencia alguna en su busca" (artículo 281 ALEC). Transcurrido el término del emplazamiento sin haber comparecido el demandado citado y acusada la rebeldía, se dará por contestada la demanda. (artículo 528 ALEC).

Una vez declarada la rebeldía, mediante providencia ${ }^{53}$ se producían sus efectos. Estos efectos eran diversos y los analizamos a continuación: a) La preclusión. La incomparecencia del demandado, voluntaria

${ }^{51}$ Respecto a la posibilidad de rebeldía del actor véase Herce Quemada, V. "La denominada rebeldía del actor en el proceso civil", en Revista Temis, 1957, pp. 79 y ss.

52 Gómez Orbaneja, Emilio. Derecho Procesal Civil. Volumen I. Madrid, 1979, p. 172

53 Artículo 369.- Las resoluciones de los Tribunales y Juzgados, en los negocios de carácter judicial, se denominarán: Providencias, cuando sean de tramitación. 
o involuntaria trae como consecuencia que se de por contestada la demanda (artículos 527 y 685 de ALEC); b) Falta de contradicción. La rebeldía no se equipara a una presunción de admisión por el sujeto pasivo de los hechos afirmados en la demanda. Ni tampoco equivale a su conformidad ${ }^{54}$. Por otra parte la rebeldía no pone término al proceso. Éste continúa y se sigue con la presencia activa del actor o demandante. Sin duda que hay una ventaja para el demandante pues no tiene un "contrincante" y se desequilibra el proceso a favor del actor. La rebeldía sólo equivale a falta de contradicción.

Uno de los temas delicados que se discutían bajo la vigencia de la antigua ley, era la posibilidad de declarar la ficta confessio al litigante declarado rebelde. Era indiscutible por la doctrina que el litigante rebelde podía ser citado a confesar en el proceso, sin embargo el juez en estos casos debía ser muy cauteloso en la utilización de la confesión ficta ${ }^{55}$.Además de los efectos ya estudiados, hemos señalado que el proceso seguía su curso normal, hasta la sentencia definitiva. La sentencia que se pronunciaba en el juicio seguido en rebeldía era notificada personalmente al litigante rebelde, cuando pueda ser habido si así lo solicitaba la parte contraria. En otro caso se hacía la notificación por estrados. (artículo 769 de la ALEC). En materia de impugnación, el litigante rebelde que se le notificaba

${ }^{54}$ Samanes Ara, Carmen. La tutela del rebelde en el proceso civil, cit. p.100

55 Bonet Navarro, Ángel. La prueba de confesión en juicio. Bosch, Barcelona, 1979, p. 267. Díaz. "Confesión judicial del demandado voluntariamente rebelde", en Revista de Derecho Procesal, 1952 № 3, pp. 71 y ss. personalmente la sentencia definitiva sólo podía utilizar contra ella el recurso de apelación y el de casación cuando proceda, si los interponía dentro del término legal. Si no había sido notificado personalmente los mismos recursos podía utilizar el litigante declarado en rebeldía. En este caso el plazo para impugnar se contaba desde el día siguiente al de la publicación de la sentencia en el Boletín Oficial de la provincia. En cuanto a su ejecución las sentencias firmes dictadas en rebeldía del demandado podían ser ejecutadas, salvo el derecho de éste para promover contra ellas el recurso de rescisión o la audiencia de litigante rebelde (artículo 787 ALEC). La antigua ley determinaba que en algunos casos, los demandados que hubieran permanecido constantemente en rebeldía y no se hallaban en ninguno de los casos de los artículos 771 y 772, se les podía conceder audiencia contra la sentencia firme que había puesto término al proceso, para obtener su rescisión y un nuevo fallo ${ }^{56}$. Esta audiencia era un medio para salir de una situación de indefensión, en la que se colocó el sujeto pasivo rebelde, en forma involuntaria, en un proceso civil ${ }^{57}$.Esta audiencia como señalaba Fernández ${ }^{58}$, tenía naturaleza análoga a la revisión, aunque se fundaba en motivos distintos y obedecía a razones muy diversas; era un medio

${ }^{56}$ De la Oliva, Andrés y Fernández, M.A. Derecho Procesal Civil. Editorial Centro de Estudios Ramón Areces. Tomo II, Madrid, 1992, p. 570

${ }^{57}$ Serrano Hoyo, Gregorio. La prohibición de indefensión y su incidencia en el proceso. Editorial Comares, Granada, 1997, p. 408.

${ }^{58}$ Fernández. M.A. (con De la Oliva, Andrés) en Derecho Procesal Civil, cit. p. 571. 
autónomo de impugnación frente a una sentencia firme ${ }^{59}$.

La Ley de Enjuiciamiento Civil ${ }^{60}$ del año 2000, regula la rebeldía en el libro II, título $\mathrm{V}$, artículos 496 y siguientes ${ }^{61}$. La doctrina ha estudiado esta nueva regulación en los respectivos comentarios a la $\mathrm{LEC}^{62}$. En el actual proceso civil español la rebeldía sigue siendo una situación jurídica que se crea por el hecho de no comparecer el demandado en el proceso. Se trata de una posición jurídica dentro del proceso que sólo puede recaer en el sujeto pasivo, demandado único o litisconsorte. En la ley vigente en España, la rebeldía se asocia con un comportamiento meramente pasivo del demandado, independiente que sea voluntaria o involuntaria. Esta incomparecencia produce la rebeldía cuando el demandado no

59 Opinión contraria, Montero Aroca, Juan (con Ortells, Manuel. y Gómez Colomer. Juan.Luis) en Derecho Jurisdiccional. Tomo II Proceso Civil, Barcelona, 1991, p. 466.

${ }^{60}$ En adelante LEC.

${ }^{61}$ Con fecha 16 de marzo del año 2002 (BOE) se publico el Real Decreto 231/2002 que regula el Registro Central de Rebeldes Civiles. Este reglamento se aplica a los demandados incluidos en el ámbito de aplicación del artículo 157 de la LEC.

62 Samanes Ara, Carmen en Comentarios a la Ley de Enjuiciamiento Civil (coord.. Cordón Moreno, F; Armenta Deu, Teresa; Muerza Esparza, Julio; Tapia Fernández, Isabel), Volumen I, Editorial Aranzadi. Elcano, 2001, pp. 1673 y ss. Illescas Rus, A en Comentarios a la nueva Ley de Enjuiciamiento Civil (coord.. Fernández-Ballesteros, Miguel angel, Rifá Soler José María, Valls Gombau), tomo II, Iurgium Editores. Barcelona, 200o, pp. 2331 y ss. Banacloche palao, Julio en Comentarios a la Ley de Enjuiciamiento Civil (con De la Oliva Santos, Andrés; Díez-Picazo Giménez, Ignacio; Vega Torres, J). Editorial Civitas. Madrid, 2001, pp. 855 y ss. Garberí Llobregat, J en Los Procesos Civiles (con Torres Fernández, Duro Ventura, Casero Linares), Volumen $3^{\circ}$, Bosch. Barcelona, 2001, pp. 943 y ss. comparezca en forma en la fecha o en el plazo señalado en la citación o emplazamiento (artículo 496.1) De acuerdo al artículo 155 de la LEC, cuando se trate del primer emplazamiento o citación al demandado los actos de comunicación (notificación) se hacen por remisión al domicilio de los litigantes ${ }^{63}$.Esta actitud del demandado adquiere el carácter de rebelde cuando aquél no comparece a la primera citación o emplazamiento, independiente de las actitudes que asuma después, en cuyo caso deja de ser rebelde. Como señala Illescas Rus ${ }^{64}$ no hay declaración de rebeldía cuando haya inasistencia a actuaciones concretas del proceso de parte de quien ya se a personado y ha sido admitido como parte, aunque se produzcan después de una citación o emplazamiento.

La rebeldía es en el proceso español la consecuencia jurídica que se produce por la no personación del demandado dentro del plazo legal, una vez que ha sido emplazado o citado. Como señala Díez-Picazo ${ }^{65}$, debe ser inicial y total, es decir hay rebeldía desde que el demandado no comparece desde un principio y a lo largo del procedimiento. En

${ }^{63}$ Puede designarse como domicilio el que aparezca en el padrón municipal o el que conste oficialmente a otros efectos, así como el que aparezca en Registro oficial o en publicaciones de Colegios profesionales, cuando se tratare, respectivamente, de empresas y otras entidades o de personas que ejerzan profesión para la que deban colegiarse obligatoriamente. También puede designarse como domicilio, el lugar en que se desarrolle actividad profesional o laboral no ocasional (artículo 155.3)

${ }^{64}$ Illescas Rus, Ángel en Comentarios a la nueva Ley de Enjuiciamiento Civil, cit. p.2336.

65 Diez-Picazo Giménez, Ignacio (con De La Oliva, Andrés) en Derecho Procesal Civil. Editorial Universitaria Ramón Areces. Madrid, 2004, p. 291. 
la LEC, al igual que en la ley antigua, los presupuestos para que se de la rebeldía en el proceso son los siguientes: Citación o emplazamiento válido.(artículo 496.1) y que el demandado no comparece en el plazo legal. En el juicio ordinario este plazo es de veinte días. En el juicio verbal si el demandado no comparece en la vista se le declara en rebeldía.

La declaración de rebeldía emana del juez que conoce del proceso, ya sea a petición del actor o de oficio. Se declara en rebeldía el demandado que no comparezca en forma en la fecha o en el plazo señalado en la citación o emplazamiento. Esta declaración se materializa en una resolución judicial que tiene la naturaleza de una providencia ${ }^{66}$. Entre los efectos principales: La declaración de rebeldía no se considera como allanamiento ni como admisión de los hechos de la demanda, salvo los casos en que la ley expresamente disponga lo contrario. Esto significa que el actor deberá probar los hechos en que funda su demanda. Si bien la rebeldía del demandado no implica allanamiento ni reconocimiento tácito de las pretensiones ejercitadas por la parte actora, recayendo igualmente sobre ésta, de conformidad con el artículo 217.2 de la LEC, la carga de probar los hechos constitutivos de su pretensión, lo cierto es que dicha rebeldía va acompañada de una lógica reducción de la actividad

${ }^{66}$ Artículo 206.2.1 ${ }^{\text {a }}$ Se dictará providencia cuando la resolución no se limite a la aplicación de normas de impulso procesal, sino que se refiera a cuestiones procesales que requieran una decisión judicial, bien por establecerlo la ley, bien por derivarse de ellas cargas o por afectar a derechos procesales de las partes, siempre que en tales casos no se exija expresamente la forma de auto. probatoria a desplegar por el actor y una menor rigurosidad en la valoración de la prueba aportada por éste, evitando así que en caso contrario la rebeldía voluntaria se convierta en una cómoda defensa para el demandado ${ }^{67}$. Ahora bien, la regla incumbit probatio qui dicit, non qui negat no alcanza un valor tan absoluto y axiomático, habiendo sido atemperada por una constante jurisprudencia consagrada ${ }^{68}$, en el sentido de afirmar que la norma distributiva del onus probandi no responde a principios inflexibles, sino que debe matizarse según las circunstancias de cada caso, la naturaleza de los hechos afirmados o negados, y la facilidad o disponibilidad para la prueba que tenga cada parte; doctrina que encuentra particular aplicación en materia de oposición tácita, dado que el rebelde no debe encontrarse, por su mera condición de tal, en una posición más favorable que quien comparece para oponerse expresamente.

Como la rebeldía no es un estado infinito, puede el demandado en cualquier tiempo comparecer. Eso si cualquiera que sea el estado del proceso en que el demandado rebelde comparezca, se entiende con él la sustanciación, sin que el proceso pueda retroceder en ningún caso. Hay en el artículo 499, una clara aplicación del principio de la preclusión. Respecto a la prueba documental, en segunda instancia, el demandado declarado en rebeldía que, por cualquier causa que no le sea imputable, se hubiere personado en los

${ }^{67}$ Sentencia de fecha 7 de febrero de 2006 del Juzgado de Primera Instancia de Murcia. Juicio verbal $\mathrm{N}^{\mathrm{o}} 1189 / 2005$.

${ }^{68}$ SSTS de 23 septiembre 1986; 15 julio 1988; 19 mayo 1993 y 6 junio 1994. 
autos después del momento establecido para proponer la prueba en la primera instancia puede pedirla en segunda instancia para que se practique toda la que convenga a su derecho. No obstante lo dicho, puede sostenerse que, de acuerdo al artículo $225 \mathrm{~N}^{\circ}$ 3 y 227.2, el demandado que se apersone en el proceso, puede alegar ante el juez la nulidad del acto de comunicación inicial, cuando éste no hubiese cumplido con los requisitos previstos en el artículo $166^{69}$.

De acuerdo a lo regulado en el artículo 500 el demandado rebelde a quien haya sido notificada personalmente la sentencia, sólo puede utilizar contra ella el recurso de apelación, y el extraordinario por infracción procesal o el de casación, cuando procedan, si los interpone dentro del plazo legal. Los mismos recursos puede utilizar el demandado rebelde a quien no haya sido notificada personalmente la sentencia, pero en este caso, el plazo para interponerlos se cuenta desde el día siguiente al de la publicación del edicto de notificación de la sentencia en los Boletines Oficiales del Estado, de la Comunidad Autónoma o de la provincia.

El demandado que permanece constantemente en rebeldía puede pretender, del tribunal que la hubiere dictado, la rescisión de la sentencia firme ${ }^{70}$ en los casos que veremos a continuación. El artículo 501 expresamente nos señala los casos que permiten ejercer esta pretensión de rescisión

69 De la misma opinión Illescas Rus, Ángel en Comentarios a la nueva Ley de Enjuiciamiento Civil, cit. p.2351.

70 No procede la rescisión de las sentencias firmes que, por disposición legal, carezcan de efectos de cosa juzgada, de conformidad al artículo 503.
(De fuerza mayor ininterrumpida, que impidió al rebelde comparecer en todo momento; De desconocimiento de la demanda y del pleito; y finalmente de desconocimiento de la demanda y del pleito, cuando el demandado rebelde haya sido citado o emplazado por edictos y haya estado ausente del lugar. Los plazos para ejercer esta pretensión se encuentran señalados en el artículo 502 de LEC. Veinte días, a partir de la notificación de la sentencia firme, si dicha notificación se hubiere practicado personalmente. Hay aquí una diferencia con la antigua ley, que no permitía este procedimiento cuando la notificación era personal.

En resumen en el nuevo proceso civil español la parte rebelde puede contradecir lo alegado por la contraparte tanto en primera como en segunda instancia, produciendo la prueba que corresponde (LE Art. 772, 773, 767). En forma explícita contempla el ordenamiento procesal el contradictorio ficto NLE (Art. 496, 497), de esta forma el tribunal tiene que pronunciar sentencia aún cuando una de las partes se encuentre declarada rebelde. Sin embargo la parte que compareció no se desprende de la carga de la prueba de sus alegaciones, esto porque la rebeldía no conduce per se a una sentencia en perjuicio del rebelde. Incluso la sentencia dictada en rebeldía no se diferencia en sus requisitos formales inmateriales de aquella que se pronunció luego de un proceso contradictorio, la fundamentación en lo que hace a la valoración de la prueba debe igualmente efectuarse.

2- En el modelo francés se distinguen dos formas de rebeldía. La primera alternativa es la no comparecencia de una de las partes, supuesto denominado défaut faute de comparaître. La segunda alternativa es la 
comparecencia pero él no cumplimiento de determinadas cargas procesales o su cumplimiento en forma parcial y defectuosa ${ }^{71}$ le defaut faute d'accomplir les actes de la procedure dans le délai ${ }^{72}$. Como puede verse el modelo abarca tanto la falta de colaboración total como la parcial. Siendo la comparecencia de las partes con patrocinio legal obligatorio, la sola designación de abogado implica para la parte la asunción de la carga de comparecencia en audiencia. Los hechos de la incomparecencia o la mera colaboración defectuosa deben ser judicialmente declarados y no es suficiente, aunque sí necesario y presupuesto para el eventual dictado de una sentencia contra de la parte rebelde. La rebeldía por sí misma no acarrea consecuencias probatorias favorables ni desfavorables para ninguna de las partes, sino que simplemente su declaración habilita a que el tribunal pueda dictar una sentencia definitiva el rebeldía ${ }^{73}$. De esta forma se impide que la falta de colaboración procesal de una de las partes

${ }^{71}$ Pierre, Julien-Fricero, Natalie, Droit judiciaire privé, LGDJ, Paris 2001; Julian, Pierre, "Jugement par défaut ou réputé contradictoire", in Répertoire de procédure civile III,. Dalloz, Paris 1997, n. 297.

72 Couchez, Gérard, Procédure civile, 14 Ed., Sirey, Paris 2007, pp. 318

73 Ver Kargados, Panagotis, op. Cit., p. 141 s.; Steinhauer, Thomas, op. Cit., p. 126. La designación de abogado es considerada como participación que purga la rebeldía. El rebelde puede incluso comparecer hasta el cierre del período de emplazamiento ordennance de clôture (o nombramiento de abogado) y aportar nuevos hechos (así se clausura la faz instructiva Couchez, Gérard, op. Cit., Nr. 261). Clausurada la instancia solo por causa grave se admite su ingreso (Couchez, Gérard, op. Cit., Nr. 263). Ante el tribunal d'intance se configura el caso de rebeldía por no comparecencia cuando ni el representante ni la parte comparecen pudiéndose ello tener lugar al inicio o en una fase posterior del proceso (Couchez, Gérard, op. Cit., Nr. 314). obstaculice el normal desenvolvimiento de la instancia obligando al juez a pronunciar una sentencia definitiva que deberá contener la debida motivación de apreciación (fundabilidad de la sentencia) de las alegaciones unilaterales de la parte compareciente, en el contexto del contradictorio ficto según el Art. 472 II y 468 $\mathrm{NCPC}^{74}$. En caso de que la sentencia sea impugnable mediante recurso de apelación o la notificación de la demanda a la parte demandada se haya efectuado en forma personal se pronuncia una sentencia en rebeldía que se reputa como contradictoria (jugement réputé contradictoire). Caso contrario la sentencia es designada simplemente como en rebeldía (jugement per défaut $)^{75}$. La regulación íntegra del proceso en rebeldía comprende mecanismos para permitir el acceso sucesivo del rebelde siempre que acredite que su falta de colaboración no le fue inputable, ello es que no tuvo culpa ${ }^{76}$. Tiene la posibilidad de acudir

${ }^{74}$ Cadiet Loïc, Code de Procédure civile, LexisnexisLitec, Paris, 2007, Art. 472, Nr. 1 y Art. 468, Nr. 1-3.

${ }^{75}$ Cadiet Loïc, Droit Judiciaire Privé, LexisnexisLitec, Paris, 2006, Nr. 1295; Julien, Pierre, op. cit., Nr. 22.

${ }^{76}$ Couchez, Gérard, op. Cit., Nr. 315-315 bis. La demanda debe ser admisible y plausible. Con la reforma de 1972 se incorpora el Art. 472 II NCPC, del cual al doctrina deriva la imposibilidad e inadmisibilidad de la confesión ficta (Julien, Pierre, op. cit., Nr. 22.). Los fundamentos de la sentencia deberán tienen igual contenido que un proceso contradictorio evaluándose la admisibilidad, y fundabilidad plenamente. Las alegaciones fácticas son sometidas a prueba y esta valorada. La necesidad de este juicio completo como si fuera una contradictorio fue confirmado por la Cour de Cassation: Cass. 2e. civ. 24 Mai 1989, Bull. Civ. II n. ${ }^{\circ}$ 116 u. Cass. 2e. civ. 21. März 1988, Bull civ. II n. ${ }^{\circ} 73$; Cass. soc., 4 /7/1990, Bull. Civ. V, n. ${ }^{\text {3 } 352 ; ~ 19 / 6 / 1991, ~}$ Bull. Civ. V, n. ${ }^{\circ} 314$; 9/12/1993, JCP 1994.IV.432. 
a un medio de impugnación especial cual es la oposición ,opposition“"77, la que en realidad se condice más bien con un mecanismo para impugnar una confesión ficta y no parece dogmáticamente el más adecuado para un contradictorio, aunque sea ficto ${ }^{78}$. En el esquema francés el rebelde no puede interponer oposición cuando procede el recurso de apelación (Décr.-L. 58-1289). Contra una sentencia en rebeldía réputé contradictoire no puede interponer oposición alguna, esto aún cuando de acuerdo al CPC de 1806 el recurso era procedente tanto para jugement par défaut como para los réputé contradictoire. Ello generó un innecesario entorpecimiento del proceso, lo que condujo a su modificación posterior del artículo 149 NCPC en 1958. De esta manera siendo procedente del recurso de apelación en el caso de réputé contradictoire, excluye toda posibilidad acumulativa, subsidiaria o alternativa de interponer oposición ${ }^{79}$.

3- En Italia - al igual como vimos en Francia - se distingue entre la no comparecencia total al proceso (contumacia) y la sola incomparecencia a una audiencia (mancata comparazione). Ello para dejar bien claro que, la rebeldía plena puede verificarse solamente al inicio del proceso. Sin embargo el proceso en rebeldía no pierde su carácter contradictorio, aún cuando eso sea simplemente una ficción. La parte rebelde debe haber sido puesta en conocimiento de las fases y actos procesales oportunamente.

77 Para las nociones de fundamento desde la perspectiva comparada de la "oposición" ver Lebre de Freitas, "Le respect des droits de la défense", op. Cit., Nr. 28.

${ }^{78}$ Cadiet Loïc, Droit Judiciaire Privé, op. cit., p. 343.

${ }^{79}$ Couchez, Gérard, op. cit., Nr. 314-315.
Sin embargo la sentencia no puede fundarse ni en una confesión tácita, ni en un reconocimiento o allanamiento presunto ${ }^{80}$. La causa debe ser resuelta previo conocimiento pleno de hecho y de derecho ${ }^{81}$. El imperativo de comparecencia es considerado por la doctrina italiana como una carga y nunca como un deber. Consecuente con ello se desprende la necesidad de partir, en caso de rebeldía, de un contradictorio presunto total y nunca de ficciones que permitan al juez eludir cuestiones probatorias ${ }^{82}$.

4- En conclusión puede verse en los sistemas influenciados por la ficta litis contestatio la manifestación de que la sola rebeldía no debe implicar para el rebelde ningún perjuicio procesal per se. Ello es, correlativamente ningún beneficio para la contraparte $^{83}$. Al juez no le es permitido

${ }^{80}$ Carpi Federico, / Taruffo, Michele, Commentario breve al Codice di procedura civile, CEDAM, Milán, 2006, Art. 290, I, Nr. 1-8, II Nr. 1-3.

${ }^{81}$ Comoglio, Luigi P.- Ferri, Corrado- Taruffo, Michele, Lezioni sul processo civile-Il processo ordinario di cognizione, Il Mulino, 2006, p 80 y ss.; Carpi, FedericoTaruffo Michele, op. Cit., Art. 290 Nr. II 3. El rebelde puede comparecer hasta la clausura de la fase instructiva, luego no hay posibilidad sino de continuar la tramitación, siendo que la consecuencia perjudicial para el rebelde se da por la preclusión de posibilidad de realizar actos en un período de tiempo. Solo mediante rescición de lo actuado pueden retrotraerse etapas (Ver los antecedentes históricos inmediatos en Costa, Sergio, "Contumacia-Diritto processuale civile", in Novissimo Digesto Italiano, T. 4, Turín, 1957, pp.772-778, p. 776). Así por la rimessione solo en casos extraordinarios y taxativos pued volverse a etapas procesales ya precluidas (Costa, Sergio, op. Cit., p. 777).

82 Cavallari, Bona Ciaccia, La contestazione nel processo civile, Giuffrè, Milano 1992, II, p. 32 e s.

${ }^{83}$ Carpi Federico, / Taruffo, Michele, op. Cit., Art. 291 II Nr. 1; comp. Carratta, Antonio, Il principio di non contestazione nel processo civile, Giuffrè, Milan, 1995, p. 292 y ss. 
inferir ningún argumento, valoración probatoria o consecuencia alguna que le sirvan de sustento para su convencimiento y motivación de la sentencia. De esta forma se excluye todo rastro o posibilidad de acudir a una confesión ficta ${ }^{84}$.

\section{EL MODELO INGLÉS COMO SISTEMA COMBINADO}

Aun cuando no se tratará en detalle diferencias y detalles teóricos en la génesis del common y equity law se deben hacer algunas aclaraciones que son relevantes para el desarrollo del sistema de rebeldía en el modelo inglés. La dualidad entre derecho común inequidad surgida con posterioridad al siglo XIV no sólo se manifestó en las normas procedimentales y orgánicas de tribunales, sino también concordancias y divergencias ideológicas y de concepción del derecho en su integridad ${ }^{85}$. Curiosamente en ambas influyó fuertemente el sistema de la litis contestatio, en tanto expansión e influencia de la visión adversarial y contractual del proceso. Esto se manifestó en una etapa inicial tanto en la consideración de la comparecencia como un deber penal y civilmente sancionable, con amplias medidas coercitivas para lograr la comparecencia y cooperación de las partes. El muy posterior el desarrollo de un proceso y de resoluciones

${ }^{84}$ Giannozi, Giancarlo, La contumacia nel processo civile, Milano, Giuffrè, 1963, p. 102 s.; Lo Cigno "La Contumacia Nel Processo Civile" (1986) 4 Giurisprudenza italiana, p. 93

${ }^{85}$ Millar, Robert Wyness, "Ficta confessio a a principle of allegation in anglo-american civil procedure", 23 Illinois Law Review 1928, pp. 215-249; Jacob, Jack, The Fabric of English Civil Justice, Londres, 1987, pp. 8-25. en rebeldía con una concepción y estructura cercana, no similar a la del sistema continental europeo. El common law preveía la falta de comparendo y la falta de cooperación del que sí compareció. Paralelamente contempló supuestos que le permitían a la parte rebelde la rectificación posterior alegando vicios procesales o causales de justificación que, debidamente acreditadas permitían al tribunal decidir positivamente su intervención posterior $^{86}$. A diferencia de éste el equity law , impregnado por el derecho canónico, contempló a la rebeldía como una consecuencia última y subsidiaria sujeta a estrictos requisitos para poder declararla: ya sea en caso de incumplimiento de una orden judicial (contempt) o en caso de total incomparecencia. La participación en el proceso fue considerada como un deber de colaboración y consecuentemente se podía recurrir a la ficción pro confesso para la motivación de la sentencia. Con la reforma del common law por la Uniformity of Process Act en 1832 y del equity mediante la Chancery Orders en 1845 comienza el acercamiento entre los dos sistemas procesales y a ello no fue ajena la regulación de la rebeldía. Es finalmente que con las Judicature Acts de 1873 y 1875 ambos procesos logran arribar a una armonización completa $^{87}$. El punto de partida en común fue no distinguir entre la rebeldía inicial y la sobreviviente en un proceso. De esta forma la sentencia en rebeldía podía darse en cualquier etapa procesal. En las Civil Procedure Rules (desde 1999) se contempla

${ }^{86}$ Tidd, William, The practice of the courts of King's Bench, and Common Pleas, in personal actions; and ejectment, Vol. 1, London 1824, p. 462.

${ }^{87}$ Millar, Robert Wyness, op. cit., p. 366. 
al instituto como default judgment en las partes 12 y $13^{88}$.

1. El fundamento de las distintas clases de rebeldía se desprende del principio adversarial en la etapa del pretrial como del trial.. De acuerdo al estado del proceso existen cuatro casos posibles de rebeldía. Los tres primeros pueden darse sólo en la etapa del pretrial, mientras que el cuarto corresponde a la del trial. Este último caso no es frecuente ya que normalmente las partes que comparece a la primera etapa, también lo harán en la segunda $(\text { trial })^{89}$. El primer caso se funda en la falta de voluntad para defenderse por parte del demandado. A los efectos de que éste sea declarado rebelde se presenta un formulario (writ) normalizado intimando al demandado al demandado su comparecencia. Siendo que el demandado no demuestre intención de defenderse frente al requerimiento puede pronunciarse sentencian rebeldía fundada en in default of giving notice of intention to defend. Especial relevancia tienen en este caso la rebeldía cuando la pretensión consiste en el pago de una suma de dinero determinada o la restitución de una cosa inmueble. En estos supuestos la determinación precisa de la prestación da certidumbre, en forma evidente en caso de una suma líquida de dinero (liquidated demand), lo que permite sin más el pronunciamiento de la sentencia y su ejecución ${ }^{90}$ en pro de dos formas. El

${ }^{88}$ O'Brien, Derek, "The New Summary Judgment: Raising the Threshold of Admission", C.J. Q., Vol. 18, 1999, p. 132 ss.

89 Jolowicz, John Anthony, "Order for Payment: English Law", In Order for Payment in the European Union, Kluwer, The Hague/London/New York 2001, p. 115.

${ }^{90}$ Ver CPR Part $12.4,12.4$, p. Part. 12.6 y 16.4; comp. White Book, 6/2/4 O. 13, r. 1- r. 4 demandante puede obtener una sentencia interlocutoria provisoria o bien una definitiva, lo que se solicita presentando un formulario de sentencia. Desde la presentación, el procedimiento en rebeldía se tiene por iniciado no siendo conocido por un juez sino por un funcionario en sus funciones equiparable a un secretario, el registrar. La demanda interpuesta no se somete a ningún examen de plausibilidad o fundabilidad alguna por parte del funcionario, pronunciándose sin más la sentencia condenatoria fundada en la ficción del reconocimiento de la pretensión del demandante por parte del rebelde. La sentencia hace cosa juzgada material y puede en todo momento ser invocada por el demandante para futuros contradictorios mediante el estoppel $^{91}$.

Un segundo caso se configura. Las partes se obligan a acompañar con la demanda (pleading) todo el material probatorio que hayan intercambiado entre demandante demandado en la fundamentación de sus posiciones en los respectivos escritos (statement of claim por el actor y defence ( contestación de la demanda) por el demandado). Así este supuesto se da cuando la parte demandada no presenta su contestación ${ }^{92}$. Debido a que la colaboración de las partes es considerada precisamente un

${ }^{91}$ CPR Part. 12.11; Comp. Kelly, David St. L., "Issue Estoppel -judgments founded on assumptions-default judgments", 84 Law Quaterly Review, 1968, pp. 362-381

92 CPR Part. 12.1: "12.1 In these Rules, “default judgment" means judgment without trial where a defendant : (a) has failed to file an acknowledgment of service; or (b) has failed to file a defence" p. también Part 13. 2 und 13.5; comp. White Book I 18/7/4; al respecto Andrews, Neil, "Accelerated Justice" under the English Civil Procedural Rules, ZZPInt 7 (2002), p. 79 ss. 
deber, la no presentación de la contestación conteniendo la totalidad del material con el cual el demandado pretende defenderse contra lo que se le requiere, permite que se constituya en un supuesto en base al cual puede dictarse una sentencia en rebeldía (judgment in default of service of a defence (pleading)). En este caso el juez debe evaluar la admisibilidad y procedencia de la demanda y sin mayor evaluación de la fundabilidad y solo sosteniéndose en este escrito sin consideraciones probatorias, dictar sentencia en rebeldía ${ }^{93}$. Siendo positivo el juicio de admisibilidad y procedencia de la demanda se consideran las alegaciones como tácitamente contestadas sin consideración a sí existe confesión o contradicción ficta. ${ }^{94}$. La tercera posibilidad de sentencia rebeldía se constituye cuando no se cumple con el deber de presentar documentos o cuando el demandado omite contentar preguntas realizadas por el actor (default in making discovery and ansuwering interrogatories). El cuarto caso es de naturaleza subsidiaria y final. Por un lado supone que no se hayan verificado ninguno de los tres casos precedentemente descriptos y por otro lado constituye técnicamente la última posibilidad dentro del proceso para poder dictar una sentencian en rebeldía. Siendo que la parte no comparece a la audiencia principal en la etapa del trial se pronuncia una sentencia en rebeldía por defecto de comparecencia (default of appearance a trial). Esta sentencia es equiparada a una pronunciada en un proceso contradictorio ${ }^{95}$.

${ }^{2}$ Así caso Webster v. Vincent (1898).

94 White Book I 19/7/10; p. Young v. Thomas (1892) 2 Ch 135. C. A.

${ }_{95}$ Part 12.11.
3. La hibrides del proceso en rebeldía inglés se nota claramente en las rigidez de los medios de impugnación (application to set aside judgment) con los que cuenta el demandado, sea vinculado a los requisitos que deben satisfacerse como a los taxativos, motivos en los que pueden fundarse ${ }^{96}$. La oposición del demandado debe ser debidamente fundada. Y ello procede en base a dos motivos: a) o la sentencia dictada en rebeldía está viciada (irregular), con lo cual el oponente gozará eventualmente del derecho de restitución ${ }^{97}$; o b) la sentencia es válida (regular) y puede ser revocada en base a la discreción ponderación del juez, no gozando el recurrente de derecho de restitución alguno ${ }^{98}$. Aún cuando explícitamente no se impida la interposición de los recursos ordinarios (Appeal), la revocación de una sentencia rebeldía puede prácticamente sólo tener lugar mediante este recurso extraordinaria. Técnicamente la appeal no estaría concebida para una sentencia dictada en rebeldía, ya que esta no constituiría una resolución judicial, que presupone un contradictorio, sino una de carácter administrativo ${ }^{99}$.

\section{VI.EL MODELO CHILENO}

Curiosamente en Chile el tópico ha pasado casi inadvertido por la doctrina, salvo

96 Jolowicz, John Anthony, "England and Wales", in Recourse against Judgement in the European Union/ Vois de recours dans l'Union européenne/Rechtsmittel in der Europäsichen Union, Kluwer, The Hage, /London/ Boston 1996, p. 91.

${ }^{97}$ CPR Part 13, al respecto Jolowicz, Recourse; comp.. Andrews, ZZPInt 7 (2002), 79 ss. (87 s.).

${ }^{98}$ Halsbury's Laws of England, Tomo 26; White Book I 13/9/14.

99 Ver por cierto el caso Vint v. Hudspith (1885) 29 Ch. D. 322 ss. . 
alguna excepción, nos referimos a la valiosa Tesis de Licenciatura de CARRASCO POBLETE ${ }^{100}$. En el Código de Procedimiento Civil ${ }^{101}$ la notificación válida de la demanda constituye el momento procesal que da inicio al plazo que tiene el demandado para defenderse o no defenderse. Los artículos 257 y ss del CPC, regulan los trámites posteriores a la admisibilidad de la demanda. Una vez admitida la demanda, el traslado decretado por el juez debe ser puesto en conocimiento, mediante notificación legal al demandado, para que la conteste. Los artículos 258 a 260 se encargan de señalar el plazo legal que tiene el sujeto pasivo para oponer excepciones dilatorias (artículo 303 y ss) o contestar la demanda (artículo 309 y ss) y dentro de ésta reconvenir (artículo 314 y ss). Todas estas normas suponen una actitud activa del sujeto pasivo. No obstante lo señalado, dentro de las actitudes que puede asumir el sujeto pasivo se encuentra también, la inactividad. El sujeto demandado no obstante haber sido puesto en conocimiento de una demanda, mediante una notificación válida, decide no actuar en el proceso. Esta actitud de inactividad del demandado se asocia con la rebeldía. $\mathrm{La}$ rebeldía en el derecho chileno no está sistemáticamente regulada por el Código. Son diversas las normas que se refieren a ella. Las rebeldías se encuentran reglamentadas en el Título VIII, del Libro I del CPC. Sin perjuicio de otras normas legales, como por ejemplo los artículos 182, 202, 248, 318, 394, 684,

${ }^{100}$ Carrasco Pobrete, Jaime Andrés, La rebeldía en el proceso civil chileno, Santiago, (Inédita, Memoria de Licenciatura presentada en la Universidad de los Andes (2004), pasim

${ }^{101}$ En adelante CPC.
698, 715 y 718. De los artículos citados podemos señalar con propiedad que la legislación procesal civil (CPC), distingue tres tipos de rebeldías. Una que se asocia con la actitud del demandado frente a la demanda; un rebeldía que se relaciona con los plazos judiciales, y una rebeldía que se produce por no realizar una actuación procesal dentro de un plazo legal.

1. Hemos señalado más arriba que una vez notificada validamente una demanda, nace para el sujeto pasivo el plazo para defenderse, ya sea oponiendo excepciones dilatorias o contestando la demanda. La notificación válida de la demanda y el plazo para defenderse constituye en nuestro derecho el emplazamiento. Nótese que el CPC no exige que el demandado deba oponer excepciones dilatorias o deba contestar la demanda. La parte demandada no está obligada a defenderse. Es una carga procesal como ha señalado la doctrina. Si el sujeto pasivo no se defiende dentro del plazo legal su no personación pasa a constituir un estado jurídico de rebeldía. Esta rebeldía a diferencia de otras legislaciones no requiere de expresa declaración judicial. Se produce de pleno derecho por el vencimiento del plazo para defenderse. El artículo 64 del CPC expresa que los plazos legales son fatales y la posibilidad de ejercer un derecho o la oportunidad para ejecutar el acto se extingue al vencimiento del plazo. En estos casos el tribunal, de oficio o a petición de parte, proveerá lo que convenga para la prosecución del juicio, sin necesidad de certificado previo. La rebeldía se produce sin necesidad de declaración judicial expresa, porque lo que el legislador exige al vencimiento del plazo 
es que el tribunal provea lo que convenga para la prosecución del proceso. Por lo tanto, vencido el plazo para contestar la demanda, el tribunal, en el juicio ordinario de mayor cuantía, de oficio o a petición de parte puede proveer lo siguiente: "vencido el plazo para contestar la demanda, traslado para la réplica", sin necesidad de señalar que el demandado está rebelde. No obstante lo señalado por seguridad jurídica es recomendable que el tribunal al dictar la resolución judicial pertinente señale que el demandado se encuentra en rebeldía. Pero insistimos eso no es necesario en nuestro derecho.

2. La rebeldía como falta de cooperación esencial produce los siguientes efectos: a) Preclusión para contestar la demanda (artículo 64); b) La actitud de inactividad se entiende como negación de los hechos afirmados por la demandante (contestación ficta de la demanda) y por lo tanto el tribunal podrá recibir la causa a prueba al existir controversia sobre hechos sustanciales y pertinentes (artículos 318, 684, 715) 102; c) Las resoluciones judiciales se notifican al rebelde por el Estado Diario (artículo 53). Sin embargo por aplicación del principio del contradictorio y de igualdad de armas la sentencia definitiva deberá notificarse a lo menos por cédula.

El litigante rebelde en cualquier momento puede apersonarse en el proceso, pero en virtud del principio de preclusión deberá

${ }^{102}$ De conformidad a la reforma procesal laboral que entre a regir en marzo del año 2008, el artículo $453 \mathrm{~N}^{\circ} 1$ del libro V del Código del Trabajo establece que si el demandado no concurre a la audiencia preparatoria el juez puede estimar los hechos contenidos en la demanda como tácitamente admitidos. Como se ve el tratamiento es distinto al CPC. No habrá en el nuevo proceso laboral una contestación tácita propiamente tal. respetar todo lo actuado en el proceso ${ }^{103}$. Lo señalado, debe entenderse sin perjuicio de lo regulado en los artículos 79, 80 y 81 . Estos casos los contempla el legislador para evitar la indefensión o violación del debido proceso $^{104}$. De acuerdo al artículo 79, puede un litigante pedir la rescisión de lo que se haya obrado en el juicio en rebeldía suya, ofreciendo probar que ha estado impedido por fuerza mayor. Este derecho sólo puede reclamarse dentro de tres días, contados desde que cesó el impedimento y pudo hacerse valer ante el tribunal que conoce del negocio. Por su parte el artículo 80 nos señala que si al litigante rebelde no se le ha hecho saber en persona ninguna de las providencias libradas en el juicio, podrá pedir la rescisión de lo obrado, ofreciendo acreditar que, por un hecho que no le sea imputable, han dejado de llegar a sus manos las copias a que se refieren los artículos 40 y 44, o que ellas no son exactas en su parte substancial. Este derecho no puede reclamarse sino dentro de cinco días, contados desde que aparezca o se acredite que el litigante tuvo conocimiento personal del juicio. Estas alegaciones del rebelde se tramitan incidentalmente y no suspenden el curso proceso y se substancian en cuaderno o expediente separado.

3. En el caso de rebeldía por no realización de una acto en el plazo señalado está regulado

${ }^{103}$ De acuerdo al artículo 398 del Código Orgánico de Tribunales, el litigante rebelde sólo podrá comparecer ante los Tribunales Superiores de Justicia representado por abogado habilitado o por procurador del número. Como no dice la ley como debe comparecer el rebelde ante los jueces de letras; deberá hacerlo de conformidad a la ley 18.120 .

${ }^{104}$ Carocca Pérez, Alex, Garantía Constitucional de la defensa procesal. JM Bosch Editor, Barcelona, 1998, p.179. 
en el artículo 78 del CPC. Vencido un plazo judicial para la realización de un acto procesal sin que éste se haya practicado por la parte respectiva, el tribunal, de oficio o a petición de parte, declara evacuado dicho trámite en su rebeldía y provee lo que conviene para la prosecución del juicio, sin certificado previo del Secretario. En este caso la rebeldía no dice relación con la inactividad del sujeto pasivo en el proceso. Aquí la rebeldía está asociada con el vencimiento de un plazo judicial, es decir con un plazo decretado por el juez para la realización de un determinado acto procesal, como ocurre por ejemplo en el caso del artículo 12 del CPC, donde el juez debe fijar un plazo razonable para el nombramiento del procurador común. Si no se realiza o ejecuta el acto procesal dentro del plazo judicial el juez debe tener por evacuado en rebeldía dicho acto y dictará la resolución judicial pertinente para la prosecución del proceso. El funcionamiento simple de la preclusión se verifica por ejemplo en los artículos 201 (apelante que no comparece), 202 (apelado rebelde), 698 (demandante que no contesta la reconvención). Casos aislados y vinculados con conductas cooperativas menores son sancionadas con la ficta confessio. Los artículos 394 y 718 se refieren al litigante rebelde que no comparece a la absolución de posiciones. Estas normas parten del supuesto que la parte no concurre a la audiencia de absolución una vez que ha sido notificado validamente. Sin duda que esta situación puede producirse tanto respecto del demandante como del demandado. Sin embargo adquiere relevancia en los casos del demandado rebelde. Al igual como sucedía en el caso español, si bien la ley permite tener por reconocidos los hechos categóricamente afirmados en el pliego de posiciones, el juez actúa por regla cauteloso al momento de resolver.

4. Las normas del actual Código de Procedimiento Civil chileno (CPC) no son uniformes en el tratamiento de la conducta no cooperativa de una parte. Así, mientras el régimen general de "Las rebeldías" sanciona con la preclusión procesal la no realización de determinado acto en determinado plazo (Tit. VIII, Libro I Código de Procedimiento Civil Chileno). Una regulación consecuente vinculado al no haber por parte del demandado contradicción substancial y pertinente sobre los hechos que versa el juicio permite dictar sentencia sin necesidad de etapa probatoria alguna (Art. 313 CPC). Sí hay consecuencias de tácito reconocimiento cuando una parte debe reconocer un documento privado (Art. 346 num. 3 CPC), para reconocer la firma o citación para confesión de deuda como gestiones preparatoria (Art. 435 inc. 2 CPC) por ejemplo. Lo cierto es que la realidad estadística de la cantidad de procesos tramitados en rebeldía (la de falta absoluta de cooperación), el tiempo excesivo de duración de los procesos para poder llegar a una sentencia definitiva y la poca eficiencia del actual sistema ejecutivo fundamentan la propuesta de su reforma.

\section{A N Á L I S I S C R Í T I C O - PONDERATIVO DE LA REBELDÍA Y SU IMPORTANCIA PARA UNA ADECUADA REGULACIÓN HACIA LA EFECTIVIDAD DEL PROCESO CIVIL.}

Aun cuando los sistemas francés, español e italiano tienen en común la no recepción de la confesión ficta como consecuencia de la 
rebeldía, varían la posición y consecuencias gravosas que asume el rebelde. Así por ejemplo España no conoce un mecanismo de impugnación similar a la opossition ni tampoco las limitaciones de los casos de rebeldía y su posibilidad de remedio como el derecho italiano. Se puede muy bien predicar en el proceso civil español el rebelde en los hechos detenta una posición más frágil que los otros ordenamientos mencionados ${ }^{105}$. Por otro lado en los tres sistemas tomados como ejemplo el rebelde puede incorporarse al proceso con posterioridad pudiendo alegar sus derechos, que no pudo hacerlo en las etapas ya precluidas. Su ingreso sucesivo impide por regla volver a fases procesales ya clausuradas debiendo participar en el estado en instancia procedimental en la que ingresó ${ }^{106}$. La ficta litis contestatio tiene un punto de partida común muy vinculado con la visión y regulación política del debido proceso en tanto derecho a ser oído. Nos explicamos, en tanto se parte de la necesidad indispensable de un contradictorio, sea este real o ficticio, siempre la relación entre la parte compareciente y el rebelde será de oposición. Esto garantizaría que la parte que compareció no tenga beneficios de sus alegaciones unilaterales, las que se considerarán siempre como no aceptadas por la contraparte, y por ello necesitada de prueba. ${ }^{107}$.

2. El Estado en ejercicio de su función jurisdiccional debe tutelar los derechos de los individuos procesalmente de forma suficientemente adecuada, oportuna, segura y eficiente. En el derecho procesal civil este

\footnotetext{
${ }^{105}$ Kargados, Panagotis, op. Cit., p. 168.

${ }^{106}$ Comp. Linke, Helmut, Op. Cit., p. 86 ss. (94 s.).

${ }^{107}$ Comp. Sateinhauer, Thomas, p. $161 \mathrm{~s}$.
}

principio institucional y constitucional trasunta en una pluralidad de principios procesales interrelacionados y actuación conjunta pero preferente. Es decir, determinados principios tienen prevalencia sobre otros de acuerdo a la técnica procesal que para la tutela de derechos materiales se establezca. Uno de los principios rectores es el dispositivo. El proceso judicial civil está a disposición de las partes para éstas lo insten y pongan en funcionamiento cuando éstas lo crean oportuno. El núcleo de la máxima o principio de disposición es el reflejo de su par en derecho privado ${ }^{108}$. La autonomía de la voluntad permite que las partes decidan el inicio, prosecución y extinción del proceso. La voluntad de las partes actúan como factor decisivo como dueños del proceso ${ }^{109}$. De esta manera el juez actúa en los límites en que es requerido, sirviendo ello de garantía de congruencia no sólo para las partes, sino como marco para la decisión judicial. Efectivamente son las partes las que determinan el cuando, como, sobre qué y contra quien se deberá tramitar un proceso ${ }^{110}$. El principio dispositivo aparte de su faz negativa en relación al juez, sino también en relación a la contraparte ${ }^{111}$. Si juez no puede actuar sin ser requerido y más allá de lo que

${ }^{108}$ Hergenröder, Kurt Wolfgang, Zivilprozessuale Grundlagen richterlicher Rechtsfortbildung, Mohr Siebeck, Berlin, 1995, p. 76 ss.

${ }^{109}$ Stickelbrock, Barbara, Die Kollision von Prozessmaximen, Heymmans, Colonia, 2002, p. 133 s.

${ }^{110}$ Hahn, Bernhard, Kooperationsmaxime im Zivilprozess?, Köln-Berlin-Bonn-Peter Lang, Múnich, 1994, p. 7-9.

${ }^{111} \mathrm{Sch}$ önfeld, Klaus Eckhard, Zur Verhandlungsmaxime im Zivilprozess und in den übrigen Verfahrensarten: die Modifikation des Prozessrechts durch d. Sozilstaatspostulat, Peter Lang, Frankfurt a Main, 198,1 p. 126. 
se le solicitó, siendo que una de las partes instó la función jurisdiccional, la falta de cooperación de la contraparte no puede impedir o entorpecer la prosecución del proceso. Cuando una parte coopera y la otra no, ello no puede ser un obstáculo para que el juez actúe y decida eventualmente incluso contra la aquel renuente a cooperar ${ }^{112}$.

2. Ahora bien, se debe buscar un punto intermedio en el cual, la combinación del principio dispositivo respetando la autonomía de la voluntad positiva de participar y colaborar en el proceso, o negativa, de no hacerlo, no impida el ejercicio de la función jurisdiccional y más aún la eficiencia de respuesta al requerimiento de tutela de un derecho ${ }^{113}$. Ese punto intermedio debe adecuarse al debido proceso, eso es dando oportunidad a las partes para ser oídas, pero no supeditando la continuidad de la tramitación a la voluntad no cooperativa unilateral de uno de los interesados ${ }^{114}$. En este caso en relación con la rebeldía se satisface el requerimiento con mínimas previsiones ex ante y ex post en relación con la sentencia en rebeldía contraria a sus intereses del rebelde. Es ésta la que constituye en realidad el punto procesal más gravoso.

Ex ante para que el fenómeno de la falta de cooperación relevante, se debe partir del presupuesto de una comunicación regular para la notificación, citación y en su caso intimación. La calidad de emplazado con la

${ }^{112}$ Schönfeld, Klaus Eckhard, op. Cit., p. 42, 140-147

${ }^{113}$ Stürner, Rolf, Die Aufklärungspflicht der Parteien des Zivilprozesses. Tübinger Rechtswissenschaftliche Abhandlungen, Tübingen, 1976, pp. 12-25; Stürner, Rolf, Richterliche Aufklärung im Zivilprozess, Siebeck, Tübingen, 1982, pp. 10-35

\footnotetext{
${ }^{114}$ Stickelbrock, Barbara, op. Cit.,. p. 134 s.
}

comunicación regular es un presupuesto común. Recién con ello puede habilitarse la rebeldía procesalmente relevante para poder dictar una sentencia incluso contra los intereses de quien habiendo sido convocado regularmente a participar en el proceso no lo hizo ${ }^{115}$. Él resguardo ex post se satisface con la puesta a disposición en favor del rebelde agraviado de mecanismos de impugnación ordinarios o extraordinarios, estrictos o flexibles en sus causales, que permitan discutir la rebeldía misma y eventualmente las consecuencias desfavorables de la sentencia.

3. Existe la necesidad de regular el tiempo muerto que genera en el proceso por la falta de colaboración participativa. Regular en definitiva la carga del tiempo y su distribución. Así como existen regulaciones sobre la "carga de la prueba", igualmente se debe distribuir equitativamente el tiempo para que, quien participa no se vea frustrado en sus derechos por aquel que no lo hace. Ahora bien quien no participa, no necesariamente actúa siempre voluntariamente. Excepcionalmente existirán causales independientes de su querer y poder. Podrá deberse a desconocer la citación a juicio porque no se lo notificó debidamente o aun habiéndoselo hecho desconoce los alcances de no comparecer. Puede encontrarse en alguna situación de imposibilidad económica ora para satisfacer lo peticionado, ora para solventar el asesoramiento jurídico de un profesional. Quizás hasta desconozca la existencia de instituciones que lo pueden asistir gratuitamente. Quizás incluso contactando a estas instituciones o a un abogado estos se comportan pocos diligentes. En definitiva existen una serie de causales que van desde el acceso mismo a la jurisdicción

${ }^{115}$ Giannozzi, Giancarlo, La Contumacia Nel Processo Civile, Giuffrè, Milano, 1963, passim. 
hasta defectos ajenos a la voluntad que pueden obstaculizar la participación de la parte, en tanto problemas de "acceso a la justicia". Estas situaciones excepcionales deben ser también contempladas. El acceso a la Justicia integra el núcleo de la seguridad jurídica. Hace a su existencia como la garantía necesaria que deben tener todos los ciudadanos e instituciones de que sus derechos podrán ser respetados y, en su caso, defendidos convenientemente, siendo ésta una responsabilidad que atañe preferentemente al Estado, pero también al sector privado relacionado directa o indirectamente con todo lo que integra el sistema ${ }^{116}$.

4. Pero no solamente esta cuestión resulta importante desde el punto de vista del sujeto activo que desea recurrir a los órganos jurisdiccionales, sino que también tiene un efecto directo sobre los potenciales causantes de violaciones de derechos o de incumplimientos de obligaciones, que incorporarán un elemento disuasivo más a su accionar cuando sepan anticipadamente que su conducta podrá ser reprimida, con celeridad y disposición, a la acción ejercida. Es importante mencionar esto último ya que, como dijimos, no se deben tratar solamente los obstáculos que existen para lograr que una requisitoria sea efectivamente atendida o de alentar un sistema en el que pueda fácilmente llegarse a los Tribunales, sino también las necesarias decisiones que permitan que, una vez planteada la acción correspondiente, ella sea considerada en tiempo y forma para no hacer ilusorios los derechos pretendidos o defendidos ${ }^{117}$. Ya nos ha demostrado la

${ }^{116}$ Rhode, Deborah., Access to Justice, Oxford University Press, Oxford, 2005, pp. 10-34.

${ }^{117}$ De Leval, George, "Les ressources de l'inversion du contentieux", in L'efficacité de la Justice Civile en Europe, Larcier, Bruxelles 2000, pp. 83-97. historia que los incumplidores de diferentes obligaciones, cuando detectan que la Justicia no da una respuesta adecuada a los derechos de sus perjudicados, se transforman en usufructuarios de la ineficiencia y se aferran a su mora bajo un supuesto paraguas de "legitimidad", hasta el momento en que se hace efectiva la sentencia, lo cual muchas veces es un tiempo suficiente como para que, el uno acomode su situación para hacer ilusorio el cumplimiento, y el otro haya perdido más que lo que, quizás más tarde, puede ganar Si efectivamente no hay participación inexcusable ¿qué alternativas seguir?. Veamos lo más elemental. En el caso de un demandante que reclame el pago de 100 frente a un demandado que solamente reconoce 50, en el actual ordenamiento procesal civil chileno no es claro si deberá proseguirse la discusión e ingresar eventualmente a la etapa probatoria y luego al juzgamiento decidiéndose sobre el todo peticionado, si bien no sujeto a contradictorio los 50. Ahora es poco razonable hacer esperar al demandante en este caso hasta la sentencia definitiva que resuelva el todo cuando una parte no es discutida. La carga del tiempo recae innecesariamente sobre el demandante quien deberá esperar una sentencia que se pronuncie sobre el todo. Sin embargo el Código Civil chileno en su artículo 1592 (el derecho sustantivo) permite que el juez ordene el pago de la cantidad de la deuda o sus accesorios mientras decide la cuestión. Aquí habría -y considero correctamente- en términos de algunos autores una satisfacción o protección jurídica anticipada ${ }^{118}$; similar disposición existe en el proceso civil italiano

${ }^{118}$ Un ejemplo no ignorado por ejemplo en el Derecho Civil Chileno, Romero Seguel, Alejandro, Curso de Derecho Procesal Civil, Ed. Jurídica de Chile, Santiago, 2006, p. 43. 
con igual interpretación ${ }^{119}$ y fortalecida con la reforma del $2005^{120}$. Igual interpretación tiene en la doctrina brasileña para el otorgamiento de tutela anticipada por parte no contradicha de la pretensión ${ }^{121}$. Ahora, qué debe entenderse por "no discutida" permanece en la legislación procesal y la interpretación jurisprudencial. ¿"No discutida" es "debe expresamente reconocer" o simplemente "basta la no discusión tácita por el silencio y/o contestación genérica sobre un quantum? ${ }^{122}$. Nuevamente la vinculación con la regulación de la rebeldía y la falta de regulación coherente del instituto por ejemplo en el Derecho Procesal Civil Chileno. Pero esta discusión no pasó desapercibida actualmente en el Reglamento Europeo del Título Ejecutivo Europeo para una regulación eficiente de los créditos no impugnados o discutidos. Igual solución se arribó en la regulación del Proceso Monitorio Europeo en el Reglamento 1896/2006 con vigencia a partir de diciembre del 2008. Cualquiera sea la tesis a la que se adhiera, el costo del tiempo no puede seguir siendo soportado quien peticiona y participa y beneficiando a quien no se opone.

5. El reconocimiento o la variante del allanamiento eximen al juez de actividad

${ }^{119}$ Carratta, Antonio, op. Cit., p. 165 Collia, Filippo, 'L' ordinanza per il pagamento di somme non contestate nel processo del lavoro", en Rivista di Dir. Proc., 1994, p. 538.

${ }^{120}$ Ver Saletti, Achilles-Tarzia, Giuseppe., Il nuovo regime delle misure cautelari e possessorie, CEDAM, Milán, 2006, pp. 18-23.

${ }^{121}$ Ver Munhos Da Cunha, Antonio, “Antecipação e Antecipações: dez anos de tutela antecipada", en Estudos de Direito Processual Civil, Homenaje a Moniz, Revista dos Tribunais, San Pablo, 2006, p. 233.

${ }^{122}$ Conf. por cierto con el fallo de CS chilena del 18 de mayo de 1959, RDJ, t. LVI, sec. $1^{\text {a }}$., p. 26. ponderativa de la prueba. En otros términos impiden que éste pueda suplir a la voluntad de las partes para dirimir un contradictorio que no existe. Con esta última alternativa el juez se concentra en el contenido de la petición reconocida o respecto de la cual se produjo el allanamiento. Se convierten de esta manera en mecanismos procesales para el logro de economía de esfuerzos y agilidad de tramitación. Se logra de esta manera una aceptable equilibrio en el balance de intereses entre celeridad y seguridad procesal ${ }^{123}$. La regla general es que en cada proceso debe probarse todo aquello que forma parte del presupuesto fáctico de la pretensión que se formula al juez, que no esté eximido de prueba por ley. Así se vincula al juez debiendo este conocer sobre lo peticionado y dentro de ese marco. Las partes podrán alegar invocando hechos constitutivos, impeditivos o extintivos ${ }^{124}$. En cuanto al silencio o rebeldía del demandado, es cuestión de política procesal el definir sus efectos. Si el requisito para que lo alegado sea objeto de prueba es principalmente que sea controvertido y una de las partes no participa debiendo hacerlo para invocar según sea para enervar lo peticionado por la contraparte, ello no puede colocarlo en la misma situación que si hubiere controvertido realmente ${ }^{125}$.

${ }^{123}$ Proto Pisani, Andrea, "Verso la residualitá dei processi a cognizione piena?", Foro Italiano, 2006, V, p. 69

${ }^{124}$ Kofmel, Sabine., Das Recht auf Beweis im Zivilverfahren, Stämpfli, Berna, 1992, pp. 15-27; Baur, Fritz., "Anspruch auf rechtliches Gehör", AcP, vol. 153, 1954, p. 393.

${ }^{125}$ Didier, Fred, "Cognição, construção de procedimentos e coisa julgada: os regimenes de formação da coisa julgada no diereito processual civil brasileiro", en Revista de Direito Processual Civil-Genesis, vol., 22, Curitiba, 2001, p. 709. 
6. La rebeldía mereció la atención del "Foro para la Reforma de la Justicia Civil de Chile" propugnando la incorporación del sistema de la ficta confessio. Así se dijo "Por fin, es indispensable regular el silencio o rebeldía procesal, en cuanto a si implica una admisión o por el contrario una negación de los presupuestos fácticos de la pretensión. Así como en los procesos modernos se sanciona la incomparecencia del actor a la audiencia preliminar o preparatoria de un juicio oral con la pérdida de su derecho material, se sanciona de contrario al demandado con una presunción de aceptación provisional de los hechos afirmados por el actor, disuasivos ambos suficientemente poderosos de un abuso del sistema jurisdiccional. Lo anterior requiere una posición normativa hasta la fecha entregada a confusas opiniones doctrinarias y jurisprudenciales..." ${ }^{126}$. En el documento elaborado por la U. de Chile (Bases, 2006) se sigue la visión adecuada en nuestro criterio "En la contestación debe el demandado pronunciarse sobre la veracidad de cada uno de los hechos alegados en la demanda y sobre la autenticidad de los documentos y cuya autoría le fuere atribuida. El silencio del demandado así como las respuestas evasivas, se tendrán como admisión de los hechos y de la autenticidad de los documentos "En el Anteproyecto de Código Procesal Civil sin embargo se adopta el sistema de la ficta litiscontestatio, dentro del esquema general de la preclusión y el reconocimiento ficto para otros actos diferentes a los de la primera comparecencia. Incorpora poco conexa la sentencia definitiva parcial. Opta el Anteproyecto por continuar con la regulación

126 "Documento del FORO para la reforma", 2006 (inédito) actual incluso en forma más inorgánica y menos sistematizada. Se elimina una regulación como la actualmente existente de “Las Rebeldías", y en un proyectado art. 254 establece "En los procesos declarativos, la rebeldía del demandado importará una negación de los hechos afirmados por el actor en su demanda”. Así se pretende seguir la visión actual que creemos no es eficiente. Ahora curiosamente en la reforma laboral se siguió la tesis que se pretende defender en esta investigación De conformidad a la reforma procesal laboral que entre a regir en marzo del año 2008, el artículo $453 \mathrm{~N}^{\circ} 1 \mathrm{del}$ libro V del Código del Trabajo establece que si el demandado no concurre a la audiencia preparatoria el juez puede estimar los hechos contenidos en la demanda como tácitamente admitidos. Como se ve el tratamiento es distinto al CPC. No habrá en el nuevo proceso laboral una contestación tácita propiamente tal.

Especial mención merece el Código Procesal Civil Modelo para Iberoamérica (1988), que también contiene la visión que en esta investigación se sostiene como plausible: “Art. 299. (Rebeldía).299.4. La rebeldía del demandado determinará que el Tribunal deba tener por admitidos los hechos alegados por el actor, en cuanto no resultaren contradichos por la prueba de autos, la que deberá igualmente ser diligenciada, en todo lo que' el Tribunal considere necesario, salvo que el proceso se refiriere a alguna de las cuestiones mencionadas en el inciso 2" del artículo 124, en cuyo caso se estará a lo que alli se dispone. Desde el momento en que el demandado fuere declarado en' rebeldía podrá disponerse, si el actor lo pidiere, el embargo de sus bienes en cuanto fuere 
necesario para asegurar el resultada del proceso. 299.5. Si el declarado rebelde es el actor, el demandado será absuelto al declarar la rebeldía, salvo si ha mediado reconvención, en cuyo caso se continuará con el proceso".

Orientación similar se plantea en los Principles of Transnational Civil Procedure (ALI/UNIDROIT, 2004): "Commencement of the Proceeding and Notice.11.3 The notice shall specify the time within which the defendant must respond and that the proceeding is brought under these Rules, and shall state that default judgment may be entered against the defendant if the defendant does not respond within the specified time. 15. Default Judgment 15.1 Default judgment shall be entered against a plaintiff who fails to prosecute the proceeding, or against another party who, without reasonable justification, does not answer within the time provided in these Rules, fails to offer a substantial answer, or fails to proceed after having answered.13. Statement of Defense; Counterclaims 13.113 .4 A party shall explicitly deny the allegations it intends to controvert. Failure to make an explicit denial is considered an admission. Facts admitted or deemed admitted need no proof, except as provided in Rule 15.2 with respect to a default judgment”. ${ }^{127}$ Así, la conducta no cooperativa implica aceptación tácita.

\section{CONCLUSIONES}

En modernos códigos esa rebeldía se traduce en una presunción de aceptación de los hechos por parte del demandado (presunción, reconocimiento tácito, confesión tácita depende de la política procesal que se

${ }^{127}$ Ver en detalle Hazard Jr., Geoffrey., "Fundamentals of Civil Procedure"en Uniform Law Review 2001, 753, p.1y ss. adopte). Ello adquiere matices definitivos si no aparecen elementos probatorios en contrario en el curso del procedimiento. Las alegaciones relativas a hechos no controvertidos, no necesitan de prueba. La rebeldía procesal debe interpretarse como aceptación provisional de los hechos expuestos por el actor, susceptible de ser desmentida con el mérito de la prueba que se rinda si la falta de cooperación luego es debidamente justificada y rescindido lo obrado en el proceso.

Una buena alternativa legislativa es la regulación combinada del modelo inglés, regulando distintas situaciones cooperativas más o menos importantes con distintas consecuencias. Por cierto la actual regulación chilena con un marco general de regulación de las "rebeldías" ofrece un punto de partida adecuado al que habría que amoldar la consecuencia de la ficta confessio en caso de incomparecencia o silencio total del requerido.

El proceso judicial civil está a servicio de las partes para éstas lo insten y lo pongan en funcionamiento. Ello se condice con el principio dispositivo y la autonomía de la voluntad dentro del proceso. El juez actúa en los límites en que es requerido, sirviendo ello de garantía de congruencia no sólo para las partes, sino como marco para la decisión judicial. Ahora si juez no puede actuar sin ser requerido y más allá de lo que se le solicitó, siendo que una de las partes instó la función jurisdiccional, la falta de diligencia cooperativa de la contraparte no puede impedir o entorpecer la prosecución del proceso. No puede ser un obstáculo para que el juez actúe y decida eventualmente incluso contra la aquel renuente a cooperar. 


\section{REFERÊNCIAS}

ANDREWS, Neil. "Accelerated Justice under the English Civil Procedural Rules", ZZPInt, vol., 7, 2002, p. 79; Baumgärtel, Gottfreid, “Ausprägung der prozessualen Grundprinzipien der Waffengleichheit und der fairen Prozessführung im zivilprozessualen Beweisrecht", en Festschrift Matscher, Manz, Viena, 1998, p. 29 y ss.

ARAGONESES ALONSO, Pedro. "Inactividad de las partes en el proceso civil", en Revista de Derecho Procesal, 1960 N $^{\circ} 3$. Bachmaier Winter Lorena. La Rebeldía en el proceso civil norteamericano y español. Servicios de publicaciones de la Facultad de Derecho de la Universidad Complutense, Madrid, 1994. Samanes Ara, Carmen. La tutela del rebelde en el proceso civil. JM Bosch Editor S.A., Barcelona, 1993. Vergé Grau, Juan. La rebeldía en el proceso civil. Librería Bosch, Barcelona, 1989.

BENTHAM, Jeremy. Rationale of Judicial Evidence Specially Applied to English Practice, J.S. Mill (Ed.) Londres, 1827, v.1, p. 34

BONET NAVARRO, Ángel. La prueba de confesión en juicio. Bosch, Barcelona, 1979, p. 267. Díaz. "Confesión judicial del demandado voluntariamente rebelde", en Revista de Derecho Procesal, 1952 No 3, pp. 71 y ss.

BÜLOW, Oskar. "Civilprozessualische Fiktionen und Wahrheiten“, AcP 62 (1879), p. 16.

BÜLOW, Oskar. Das Geständnissrecht: Ein Beitrag zur allgemeinen Theorie der Rechtshandlungen, Mohr, Freiburg, pp. 1-21.

CADIET, Loïc. "Civil Justice Reform: Access, Cost and Delay" en Civil Justice in Crisis: Comparative Perspectives of Civil Procedure, Oxford University Press, Oxford, 1999, p. 54.

CADIET, Loïc. Code de Procédure civile, Lexisnexis-Litec, Paris, 2007, Art. 472, Nr. 1 y Art. 468, Nr. 1-3.

CADIET, Loïc. Droit Judiciaire Privé, Lexisnexis-Litec, Paris, 2006, Nr. 1295; Julien, Pierre, op. cit., Nr. 22.

CAROCCA PÉREZ, Alex. Garantía Constitucional de la defensa procesal. JM Bosch Editor, Barcelona, 1998, p.179.
CARPI, Federico, TARUFFO, Michele. Commentario breve al Codice di procedura civile, CEDAM, Milán, 2006, Art. 290, I, Nr. 1-8, II Nr. 1-3.

CARRASCO, Pobrete; ANDRÉS, Jaime. $L a$ rebeldía en el proceso civil chileno, Santiago, (Inédita, Memoria de Licenciatura presentada en la Universidad de los Andes (2004), pasim

CARRATTA, Antonio. Op. Cit., p. 165 Collia, Filippo, "L'ordinanza per il pagamento di somme non contestate nel processo del lavoro", en Rivista di Dir. Proc., 1994, p. 538.

CAVALLARI, Bona Ciaccia. La contestazione nel processo civile, Giuffrè, Milano 1992, II, p. 32 e s.

CLAYTON, Richard; TOMLINSON, Hugh. Fair Trial Rights, Oxford University Press, Oxford, 2001, pp. 8-20.

COUCHEZ, Gérard. Procédure civile, 14 Ed., Sirey, Paris 2007, pp. 318

CPR Part 12.4,12.4, p. Part. 12.6 y 16.4; comp. White Book, 6/2/4 O. 13, r. 1- r. 4

CPR Part 13, al respecto Jolowicz, Recourse; comp.. Andrews, ZZPInt 7 (2002), 79 ss. (87 s.).

CPR Part. 12.1: "12.1 In these Rules, "default judgment" means judgment without trial where a defendant : (a) has failed to file an acknowledgment of service; or (b) has failed to file a defence" p. también Part 13. 2 und 13.5; comp. White Book I 18/7/4; al respecto Andrews, Neil, "Accelerated Justice" under the English Civil Procedural Rules, ZZPInt 7 (2002), p. 79 ss.

CPR Part. 12.11; Comp. Kelly, David St. L., "Issue Estoppel -judgments founded on assumptions-default judgments", 84 Law Quaterly Review, 1968, pp. 362-381

DE LA OLIVA, Andrés y FERNÁNDEZ, M.A. Derecho Procesal Civil. Editorial Centro de Estudios Ramón Areces. Tomo II, Madrid, 1992, p. 570

DE LEVAL, George. "Les ressources de l'inversion du contentieux", in L'efficacité de la Justice Civile en Europe, Larcier, Bruxelles 2000, pp. 83-97. 
DE OLIVEIRA, Carlos Alberto Álvaro.

"O Formalismo-Valorativo no confronto com o formalismo excessivo", en Revista Forense n. 388 (2007), pp. 11-98.

DIDIER, Fred. "Cognição, construção de procedimentos e coisa julgada: os regimenes de formação da coisa julgada no diereito processual civil brasileiro", en Revista de Direito Processual Civil-Genesis, vol., 22, Curitiba, 2001, p. 709.

DIDONE, Antonio. Equa riparazione e ragionevole durata del processo, Giuffrè, Milano 2002, p. 171; ZUCKERMAN, Adrian, "Dismissal for Delay - the Emergence of a New Philosophy of Precedure" (1998) 17 Civil Journal Quaterly, p. 223

DIEZ-PICAZO GIMÉNEZ, Ignacio (con DE LA OLIVA, Andrés) en Derecho Procesal Civil. Editorial Universitaria Ramón Areces. Madrid, 2004, p. 291.

FAIRÉN GUILLÉN, Victor. El juicio ordinario y los procesos rápidos, Barcelona: Bosch, 1953, p. 149 y ss.; FAIRÉN GUILLÉN, Victor. El desistimiento y su bilateralidad en primera Instancia (contra la doctrina de la litis contestatio), Barcelona, Bosch, 1950, pp. 69-77. Ver igualmente Sohm Jr., Rudolf, Die Litis Contestatio in Ihrer Entwiclung vom frühen -Mittelalter bis zur Gegenwart, Munich, 1914, pp. 68 ss., 159 ss., 167 ss

FASCHING, Hans. "Der mühsame Weg zur Prozessbeschleunigung", in FS Beys, I, Economica, Atenas, 2003, p. 305 ss.

FASCHING, Hans. "Rechtliches Gehör und Rationalisierung des zivilgerichtlichen Verfahrens in Österreich“, en Festschrift Hideo Nakamura, Seibundo, Tokyo, 1996, p. 133;

Matscher, Franz, "Zum Problem der überlangen Verfahrensdauer in Zivilrechtssachen-Art. 6 Abs. 1 EMRK und das österreichische Zivilgerichtliche Verfahren", en Festschrift Fasching, Manz, Viena, 1988, p. 21.

FERNÁNDEZ, M.A. (con DE LA OLIVA, Andrés) en Derecho Procesal Civil, cit. p. 571.

GIANNOZI, Giancarlo, La contumacia nel processo civile, Milano, Giuffrè, 1963, p. 102 s.;
Lo Cigno "La Contumacia Nel Processo Civile" (1986) 4 Giurisprudenza italiana, p. 93

GOLDSCHMIDT, James. Der Prozess als Rechtslage, Springer, Berlin, 1925, pp. 103, 146. GÓMEZ ORBANEJA, Emilio. Derecho Procesal Civil. Volumen I. Madrid, 1979, p. 172 HAHN, Bernhard. Kooperationsmaxime im Zivilprozess?, Köln-Berlin-Bonn-Peter Lang, Múnich, 1994, p. 7-9.

Halsbury's Laws of England, Tomo 26; White Book I 13/9/14.

HAZARD Jr., Geoffrey. "Court Delay: Toward New Premises", en Civil Justice Quarterly, vol. 5, 1986, p. 236; ZUCKERMAN, Adrian, "Dismissal for Delay - the Emergence of a New Philosophy of Procedure", (1998) 17 Civil Justice Quarterly, p. 223

HAZARD Jr., Geoffrey. "Rationing Justice", Journal of Law and Economics, vol. VIII, 1965, pp. 1-10.

HAZARD Jr., Geoffrey. "Fundamentals of Civil Procedure"en Uniform Law Review 2001, 753, p.1y ss.

HERCE QUEMADA, V. "La denominada rebeldía del actor en el proceso civil", en Revista Temis, 1957, pp. 79 y ss.

HERGENRÖDER, Kurt Wolfgang. Zivilprozessuale Grundlagen richterlicher Rechtsfortbildung, Mohr Siebeck, Berlin, 1995, p. 76 ss.

JAVIER, Alvarado Planas y GONZALO, Oliva Manso. Los Fueros de Castilla, en Boletín Oficial del Estado. Centro de Estudios Políticos y Constitucionales, 2004, p. 557.

JOLOWICZ, John Anthony. "England and Wales", in Recourse against Judgement in the European Union/Vois de recours dans l'Union européenne/Rechtsmittel in der Europäsichen Union, Kluwer, The Hage, /London/Boston 1996, p. 91.

JOLOWICZ, John Anthony. "Order for Payment: English Law”, In Order for Payment in the European Union, Kluwer, The Hague/ London/New York 2001, p. 115. 
KLEIN, Franz. "Zeit- und Geistesströmungen", en Reden, Vorträge, Aufsätze, Briefe, Manz, Viena, 1927.

KLICKA, Thomas. "Die österreichische Zivilverfahrens-Novelle 2002 als Versuch einer Verfahrensbeschleunigung - ein Vergleich zur deutschen ZPO-Reform 2002", ZZPInt 7 (2002), p. 179 ss.

KOFMEL, Sabine. Das Recht auf Beweis im Zivilverfahren, Stämpfli, Berna, 1992, pp. 1527; Baur, Fritz., "Anspruch auf rechtliches Gehör”, AcP, vol. 153, 1954, p. 393.

LENT, Friedrich. "Zur Untersuchung von Lasten und Pflichten der Parteien im Zivilprozes“, en ZZP 67 (1954), p. 344.

LENT, Friedrich. "Die Verteilung der Verantwortlichkeit unter Gericht und Parteien im Zivilprozess“, en ZZP 63 (1943), p. 1

MILLAR, Robert Wyness. "Ficta confessio a a principle of allegation in anglo-american civil procedure", 23 Illinois Law Review 1928, pp. 215-249; Jacob, Jack, The Fabric of English Civil Justice, Londres, 1987, pp. 8-25.

MUNHOS DA CUNHA, Antonio. "Antecipação e Antecipações: dez anos de tutela antecipada", en Estudos de Direito Processual Civil, Homenaje a Moniz, Revista dos Tribunais, San Pablo, 2006, p. 233.

O'BRIEN, Derek. "The New Summary Judgment: Raising the Threshold of Admission", C.J. Q., Vol. 18, 1999, p. 132 ss.

PIERRE, Julien; FRICERO, Natalie. Droit judiciaire privé, LGDJ, Paris 2001; JULIAN, Pierre, "Jugement par défaut ou réputé contradictoire", in Répertoire de procédure civile III,. Dalloz, Paris 1997, n. 297.

PROTO PISANI, Andrea. "Verso la residualitá dei processi a cognizione piena?", Foro Italiano, 2006, V, p. 69.

RECHBERGER, Walter; KODEK, Georg. "General Report", in Order for Payment in the European Union, Kluwer, The Hague/London/ New York, 2001, p. 1 y ss.; Frauenberger, Andreas, "Die ZVN 2002-Neuerungen im Zivilprozessrecht“, ÖJZ 2002, p. 873 y ss.
RESNIK, Judith. Process of the Law, Foundation Press, Nueva York, 2004, p. 5 y s.; FASCHING, Hans., "Die Bedeutung des Gleichheitssatzes für das zivilgerichtliche Verfahren", en Grund - und Freiheitsrechte in der gerichtlichen Praxis- Richterwoche, Manz, Viena, 1992, p. 339.

RHODE, Deborah. Access to Justice, Oxford University Press, Oxford, 2005, pp. 10-34.

ROMERO SEGUEL, Alejandro. Curso de Derecho Procesal Civil, Ed. Jurídica de Chile, Santiago, 2006, p. 43.

SALETTI, Achilles; TARZIA, Giuseppe. Il nuovo regime delle misure cautelari e possessorie, CEDAM, Milán, 2006, pp. 18-23.

SCHIMA, Hans. Die Versäumnis im Zivilprozess, Kleinfeller, Viena, p. 3; KARGADOS, Panagiotis, Die Probleme des Versäumnisverfahrens: eine rechtsvergleichende Untersuchung anläßlich des neuen griechischen Versäumnisverfahrens, FUBerlin, Berlin, 1970, p. 1; Comp. Lebre de Freitas José, "Le respect des droits de la défense", op. Cit., Nums. 15-16.

SCHÖNFELD, Klaus Eckhard. Zur Verhandlungsmaxime im Zivilprozess und in den übrigen Verfahrensarten: die Modifikation des Prozessrechts durch d. Sozilstaatspostulat, Peter Lang, Frankfurt a Main, 198,1 p. 126.

SERRANO HOYO, Gregorio. La prohibición de indefensión y su incidencia en el proceso. Editorial Comares, Granada, 1997, p. 408.

SHAVELL, Steven. Civil Procedure and Society, Joumal of Legal Studies, 1997, 606; sobre el pensamiento de la eficiencia en la prestación de justicia ver la obra de Fiz-Fierro, Héctor, Tribunales, justicia y eficiencia, UNAM, Méjico, 2006, esp. pp. 329-332

STEINHAUER, Thomas. Versäumnisurteil in Europa: eine rechtsvergleichende Studie über die Versäumnisverfahren im deutschen, österreichischen, französischen, italienischen und englischen Recht anlässlich eines Entwurfs zur Schaffung einer einheitlichen europäischen Zivilprozessordnung, Frankfurt a. M., 1996. 
STEINWENTER, Anton. Studien zum römischen Versäumnisverfahren, Beck München, 1914, pp. 1-35.

STICKELBROCK, Barbara. Die Kollision von Prozessmaximen, Heymmans, Colonia, 2002, p. $133 \mathrm{~s}$.

STÜRNER, Rolf. Die Aufklärungspflicht der Parteien des Zivilprozesses. Tübinger Rechtswissenschaftliche Abhandlungen, Tübingen, 1976, pp. 12-25; Stürner, Rolf, Richterliche Aufklärung im Zivilprozess, Siebeck, Tübingen, 1982, pp. 10-35

TIDD, William. The practice of the courts of King's Bench, and Common Pleas, in personal actions; and ejectment, Vol. 1, London 1824, p. 462.
VOLPINO, Diego. "Contraddittorio Ed Impugnazione Incidentale Nel Procedimento Contumaciale", 2001, en NGCC, p 713 especialmente sobre la combinación entre "giusto processo" de la Constitución (art. 111) y el imperativo de "più sollecito e leale svolgimento del processo"; igualmente Lebre de Freitas, José., "Le respect des droits de la défense lors de l'introduction de l'instance", en L'efficacité de la Justice Civile en Europe, Larcier, Bruxellas, 2000, p. 13.

White Book I 19/7/10; p. Young v. Thomas (1892) 2 Ch 135. C. A.

ZUCKERMAN, Adrian. Civil Procedure, Lexisnexis, Londres, 2003, pp. 1-10. 